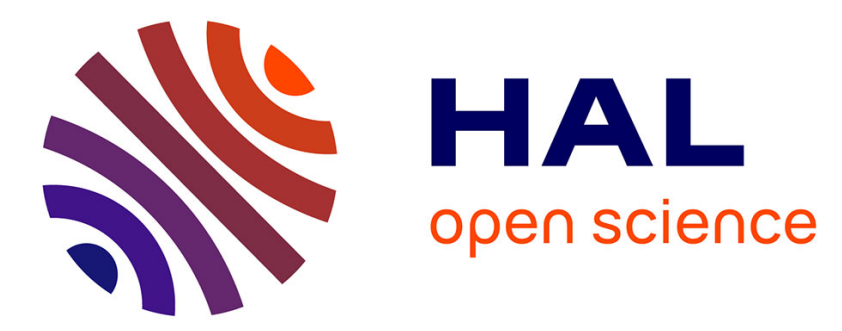

\title{
Performance and degradation mechanisms of CLC particles produced by industrial methods
}

Arnold Lambert, Airy Tilland, William Pelletant, Stéphane Bertholin, Florent Moreau, Isabelle Clemençon, Mahdi Yazdanpanah

\section{- To cite this version:}

Arnold Lambert, Airy Tilland, William Pelletant, Stéphane Bertholin, Florent Moreau, et al.. Performance and degradation mechanisms of CLC particles produced by industrial methods. Fuel, 2018, 216, pp.71 - 82. 10.1016/j.fuel.2017.11.115 . hal-01844567

\section{HAL Id: hal-01844567 \\ https://hal-ifp.archives-ouvertes.fr/hal-01844567}

Submitted on 19 Jul 2018

HAL is a multi-disciplinary open access archive for the deposit and dissemination of scientific research documents, whether they are published or not. The documents may come from teaching and research institutions in France or abroad, or from public or private research centers.
L'archive ouverte pluridisciplinaire HAL, est destinée au dépôt et à la diffusion de documents scientifiques de niveau recherche, publiés ou non, émanant des établissements d'enseignement et de recherche français ou étrangers, des laboratoires publics ou privés. 


\title{
PERFORMANCE AND DEGRADATION MECHANISMS OF CLC PARTICLES PRODUCED BY INDUSTRIAL METHODS
}

\author{
Arnold Lambert $^{\mathrm{a} *}$, Airy Tilland ${ }^{\mathrm{a}}$, William Pelletant ${ }^{\mathrm{a}}$, Stéphane Bertholin ${ }^{\mathrm{a}}$, Florent \\ Moreau $^{\mathrm{a}}$, Isabelle Clemençon ${ }^{\mathrm{a}}$, Mahdi Yazdanpanah ${ }^{\mathrm{b}}$ \\ ${ }^{a}$ IFP Energies nouvelles, BP3,69360 Solaize, France \\ ${ }^{b}$ Total, Research \& Technology Gonfreville (TRTG), 76700 Harfleur, France \\ *Corresponding Author, arnold.lambert@ifpen.fr \\ airy.tilland@ifpen.fr; william.pelletant@ifpen.fr; stephane.bertholin@ifpen.fr; \\ florent.moreau@ifpen.fr; isabelle.clemençon@ifpen.fr; mahdi.yazdanpanah@total.com
}

\begin{abstract}
A promising copper based oxygen carrier produced using industriallyrelevant manufacturing equipment has been aged in IFPEN's $10 \mathrm{~kW}_{\text {th }}$ Chemical Looping Combustion pilot plant. Methane combustion was performed at $900^{\circ} \mathrm{C}$ for $160 \mathrm{~h}$ with an $\mathrm{OC} /$ fuel ratio of 1.2 . While full methane conversion to $\mathrm{CO}_{2}$ and water was achieved in the early stage of the experiment, fast deactivation was observed. The oxygen carrying particles were thoroughly characterized at various stages of the ageing experiment, from which a pathway leading to deactivation is proposed.
\end{abstract}

Keywords : Chemical Looping Combustion; Oxygen carrier ageing; $\mathrm{CuO} / \mathrm{Al}_{2} \mathrm{O}_{3}$; degradation mechanisms. 


\section{Introduction}

In the context of global warming, Carbon Capture and Storage (CCS) has to be implemented to limit $\mathrm{CO}_{2}$ emissions from fossil fuel power plants in order to minimize the accumulation of this greenhouse gas in the atmosphere. ${ }^{1}$ Among the various $\mathrm{CO}_{2}$ capture technologies being developed, chemical looping combustion (CLC) is one of the most promising since it allows for $\mathrm{CO}_{2}$ separation with minimal energy penalty. The process relies on circulating metal oxides which act as oxygen carriers (OC) between an oxidation and a reduction reactor. ${ }^{2}$ Numerous synthetic materials, natural ores, and industrial waste materials have been reported as suitable oxygen carriers for the CLC process both in terms of oxygen transfer capacity and reaction rates. ${ }^{2}$ However, chemical reactivity and particle attrition has been investigated in most cases for a limited number of cycles, and long term ageing has rarely been investigated over hundreds of redox cycles, with the noticeable exception of Ni based particles. ${ }^{3}$

The ageing mechanism of oxygen carriers is not fully understood yet, but in the past few years, reports on the drastic morphological evolution of oxygen carrying particles due to successive redox cycles started to appear, ${ }^{4}$ pointing out that phase segregation phenomena and the increase in particles' porosity may stem from sintering and ionic diffusion within the particles. ${ }^{5}$ In order to properly evaluate different oxygen carriers lifetime, it is therefore necessary to test them for a long enough period of time (i.e. a large enough number of redox cycles) and to thoroughly characterize the aged particles. $\mathrm{Cu}$ based particles prepared at the lab scale have already been tested in different circulating fluidized bed CLC pilot plants at the Instituto de Carboquimica (CSIC Saragossa) ${ }^{6,7}$ and at the Vienna University of Technology. ${ }^{8}$ Up to $100 \mathrm{~h}$ test runs at $800^{\circ} \mathrm{C}$ were performed, of which $60 \mathrm{~h}$ corresponded to combustion. ${ }^{7}$ Methane conversion was complete throughout the test runs, providing the $\mathrm{OC} /$ fuel ratio was maintained above 1.5. The particles were characterized by different techniques, which indicated that the copper content decreased over the first half of the test, the pore size 
distribution increased slightly, while the BET surface area decreased, and the $\gamma-\mathrm{Al}_{2} \mathrm{O}_{3}$ support tended to form $\alpha-\mathrm{Al}_{2} \mathrm{O}_{3}$. The attrition rate was rather high at the beginning of the test, and stabilized to a low value of $0.04 \mathrm{wt} \% / \mathrm{h}$.

As part of the FP7 SUCCESS project, a promising copper based OC formulation selected during the FP7 INNOCUOUS project, has been produced by the Johnson Matthey Company using industrial scale manufacturing tools and commercially available alumina particles, in sufficient amounts for it to be tested in various CLC pilot plants by the different partners of the project. Cabello et al. have tested this $\mathrm{OC}$ in their $500 \mathrm{~W}_{\text {th }}$ CLC pilot plant. ${ }^{9}$ Depending on the combustion temperature, different behaviors were observed : at $800^{\circ} \mathrm{C}$, the $\mathrm{OC}$ performed well in terms of combustion efficiency and mechanical stability at $\mathrm{OC} /$ fuel ratios over 1.5 . The run was performed for $60 \mathrm{~h}$, without fluidization/agglomeration problems and with little attrition. When the combustion temperature was increased to $900^{\circ} \mathrm{C}$, the combustion efficiency was better than at $800^{\circ} \mathrm{C}$, but the mechanical stability was greatly degraded, and significant attrition was observed after $\sim 50 \mathrm{~h}$ of combustion. Characterization of the OCs was performed before and after test, with an emphasis on the particles tested at $800^{\circ} \mathrm{C}$.

The results presented in this paper were obtained with the same OC in IFPEN's $10 \mathrm{~kW}_{\text {th }}$ CLC pilot plant. The manufactured particles were fluidized for $212 \mathrm{~h}$ between 800 and $900^{\circ} \mathrm{C}$, of 65 which $160 \mathrm{~h}$ corresponded to methane combustion at $900^{\circ} \mathrm{C}$, and the $\mathrm{OC}$ particles were 66 thoroughly characterized at various stages of the ageing campaign. No fresh OC was added 67 during the test to make sure that all the particles had the same average ageing history, which 68 limited the total ageing time due to solid losses. The ageing temperature of $900^{\circ} \mathrm{C}$ was chosen 69 to allow the comparison of the oxygen carrier's performance with that of $\mathrm{Ca}_{\mathrm{x}} \mathrm{Mn}_{\mathrm{y}} \mathrm{Ti}_{\mathrm{z}} \mathrm{O}_{3-\delta} 70$ perovskite particles also studied within the SUCCESS project, for which the reduction 71 temperature should be at least 9009 C. 


\section{Experimental}

\subsection{Pilot plant}

A schematic view of the $10 \mathrm{~kW}_{\text {th }}$ CLC pilot unit used in this study is shown in Figure 1. The pilot is composed of three interconnected bubbling fluidized bed reactors. Two fluidized bed reactors (AR1 and AR2) are dedicated to the oxygen carrier oxidation and the last one (FR) is dedicated to fuel combustion, therefore performing OC reduction. More details on the design and dimensions of this unit can be found in reference. ${ }^{10}$ Recently, the unit has been equipped with a carbon stripper for combustion of solid fuels. The reduced particles go through the carbon stripper before entering the air reactor AR1, which has been implemented to separate unburnt carbon compounds from OC in the case of solid fuels combustion and is designed to separate particles with diameters below $100 \mu \mathrm{m}$. In addition, the operation of the pilot plant was automated so that it can be operated with minimal intervention of operators. This allows to perform continuous long term particle ageing tests for a few hundred hours.

The CLC pilot unit is equipped with three multi-gas online analysers. $\mathrm{CH}_{4}, \mathrm{CO}$ and $\mathrm{CO}_{2}$ concentrations are continuously measured at the outlet of the FR by non-dispersive infrared analyzers (ABB-URAS 26), while $\mathrm{H}_{2}$ concentration is analyzed by a thermal conductivity detector (ABB-Aldos 27). In $\mathrm{AR} 1, \mathrm{CO}, \mathrm{CO}_{2}$ and $\mathrm{O}_{2}$ concentrations are determined by a combined NDIR-paramagnetic analyser (ABB-Uras 26 /Magnos 206). Finally in $\mathrm{AR}_{2}, \mathrm{O}_{2}$ is measured by an electrochemical cell analyzer (Siemens - Ultramat 23). All data are collected by means of a PLC which is connected to a computer. 


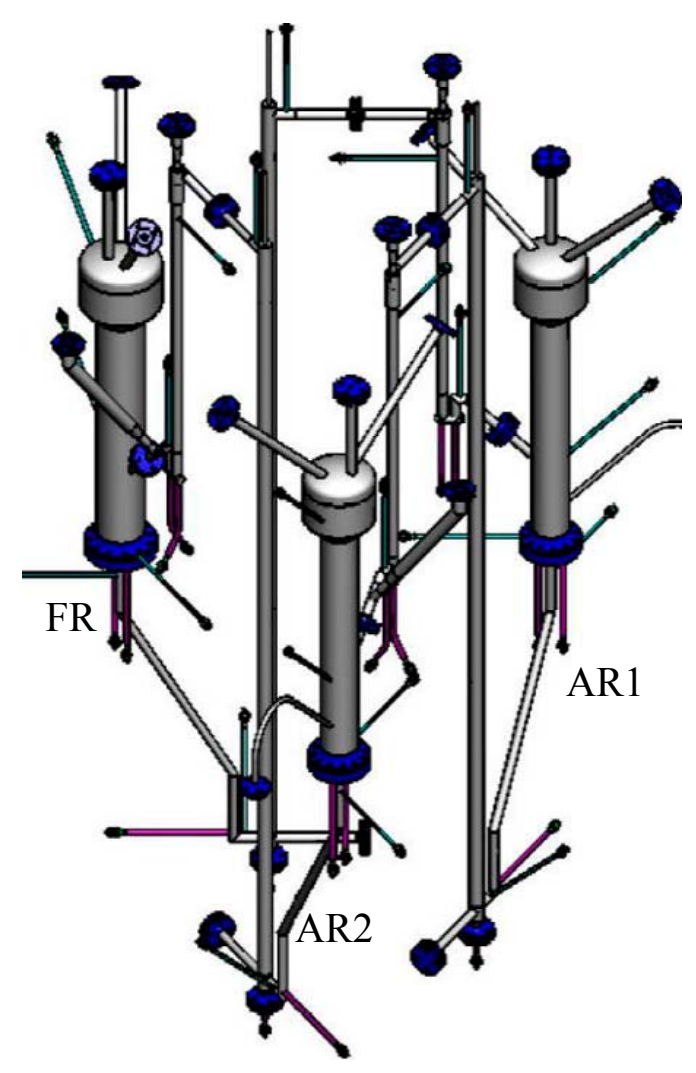

Figure 1. 3D scheme of the pilot plant

\subsection{Operating conditions}

The test presented in this paper focuses on the ageing of the oxygen carrier at $900^{\circ} \mathrm{C}$ over time. The oxygen carrier was used as supplied by Johnson Matthey. The pilot plant was filled with $18 \mathrm{~kg}$ of the material distributed among the three reactors.

During the test, part of the solid was continuously leaving the pilot plant with the gas at the carbon stripper or the cyclones. The accumulated OC was collected periodically. A small part of this powder was kept as sample for analysis and the rest was sieved. Particles with a diameter higher than $100 \mu \mathrm{m}$ were reintroduced in the pilot plant while the remaining particles (under $100 \mu \mathrm{m}$ ) were discarded. Very fine particles (under $10 \mu \mathrm{m}$ ) were also collected periodically on filter candles at the outlet of each reactor. The quantities of fine particles were always negligible compared to the amount of solid leaving the unit in the carbon stripper and the cyclones. 
No fresh material has been added in the unit during this experiment. Thus, the total solid mass in the pilot plant decreased over time but the solid was homogeneous in terms of ageing.

Besides, in order to avoid variation of gas and solid residence time in the fuel reactor, the operating conditions have been chosen to maintain a constant solid level in the fuel reactor during the entire experiment's duration. The fuel reactor was thus filled with $5.45 \mathrm{~kg}$ of solid from the start to the end of the experiment. At the beginning of the experiment, both air reactors are filled at their maximum capacity. The solid level in the air reactors (AR1 and AR2) decreased over time since samples were kept for analysis and some solid was lost with the fines produced by attrition, but the solid level of AR1 was kept equal to that of AR2 during the test. The experiment had to be terminated when the solid level in the air reactors was too low to operate without fluidization troubles.

The combustion of $170 \mathrm{Nl} / \mathrm{h}$ of methane diluted in $430 \mathrm{Nl} / \mathrm{h}$ of nitrogen has been carried out at $900^{\circ} \mathrm{C}$ with a constant solid flowrate of $20 \mathrm{~kg} / \mathrm{h}$ in the pilot plant, which corresponds to an $\mathrm{OC} /$ fuel ratio as defined by de Diego et al. $^{7}$ of 1.2 . The OC is totally oxidized in the air reactors, both operating with $1.5 \mathrm{Nm}^{3} / \mathrm{h}$ of air. The gas phase leaving the reactors has been analyzed during the entire experiment duration and solid samples have been collected regularly in order to characterize the solid evolution over time. Mass balances were performed in order to characterize the combustion efficiency of the process over time. The mass balance on carbon was performed by integrating the concentration profiles of $\mathrm{CO}, \mathrm{CO}_{2}$ and $\mathrm{CH}_{4}$ at the outlet of the fuel reactor and the concentration of $\mathrm{CO}_{2}$ and $\mathrm{CO}$ at the outlet of the air reactors. The water produced in the fuel reactor (during at least 10 hours for each mass balance) was collected in the condenser and weighed. The integration of the gaseous components at the outlet of the fuel and air reactors and the quantity of water produced allowed to check the oxygen mass balance. Hydrogen mass balance was also checked. The mass balances are numbered from 1 to 8 in the experimental results part. 


\subsection{Oxygen carrier characterization}

XRD analysis of the samples was performed using a PANalytical X'Pert Pro Diffractometer $134 \mathrm{n}$ i Bragg-Brentano configuration (CuK $\alpha$ radiation).

Scanning Electron Microscopy (SEM) imaging was performed on a CARL ZEISS SUPRA 40 microscope operating at $15 \mathrm{kV}$. Prior to cross-cut section analysis, samples were embedded into epoxy resin and polished with $\mathrm{SiC}$ discs to obtain polished sections.

Quantitative chemical X-ray maps were performed on a FEI Nova nanoSEM 450 scanning electron microscope equipped with an Oxford XMAX 80 EDS detector and operating at $15 \mathrm{kV}$. Results show the quantitative repartition of each element in mass percent.

Mercury porosimetry experiments were performed using Micromeritics' Autopore IV device after sample pre-treatment (in an oven at $250^{\circ} \mathrm{C}$ for two hours). Intrusion curves were measured up to a maximum pressure of $400 \mathrm{MPa}$ using a $\mathrm{Hg}$ surface tension of 485 dyne/cm and a contact angle of 140 degree.

BET surface area measurements were performed on a Micromeritics ASAP2420 apparatus, using $\mathrm{N}_{2}$ as a probe. Prior to measurement, the samples were pre-treated at $350^{\circ} \mathrm{C}$ for three hours under secondary vacuum $\left(10^{-6} \mathrm{~mm} \mathrm{Hg}\right)$ to remove the physisorbed species.

Attrition measurements were performed with IFPEN's jet cup, using the method developed by Amblard et al. ${ }^{11} .50 \mathrm{~g}$ of sample was used for each measurement, with an air jet velocity of $90 \mathrm{~m} / \mathrm{s}$. The Total Particles Generated Index (TPGI, an attrition index that does not depend upon a given particle size and which is based on the total percentage of particles generated by attrition, see ${ }^{11}$ ) has been measured for test durations of 2 and $3 \mathrm{~h}$.

Semi-quantitative X-ray fluorescence analysis was performed on Perform'X (wavelengthdispersive $-\mathrm{X}$ ray-Spectroscopy ) and calculated with Uniquant Sofware commercialized by Thermo Fisher Scientific. 
A symmetric SETARAM TAG24 thermobalance was used to simulate CLC redox cycles, with $25 \mathrm{mg}$ of samples in a platinum crucible. The samples were heated under air to $900^{\circ} \mathrm{C}$, then they were alternatively exposed to reducing $\left(10 \% \mathrm{CH}_{4}, 25 \% \mathrm{CO}_{2}, 65 \% \mathrm{~N}_{2}\right)$ and oxidizing (air) conditions. Nitrogen was introduced in between oxidizing and reducing periods to avoid mixing of methane and air. The reactive gas flow in the sample reactor was set at $150 \mathrm{ml} / \mathrm{min}$ (STP) using mass flow controllers, and the balance head was protected by argon flowing at $26 \mathrm{ml} /$ $\min (\mathrm{STP})$. Ten reduction-oxidation cycles were performed at $900^{\circ} \mathrm{C}$ with each sample.

\section{Results and discussion}

\subsection{Performance of the OC during ageing test}

The experimental results obtained during this test are summarized in Figure 2 and Figure 3. The oxygen carrier has circulated for 10 days and combustion of methane has been carried out during almost $160 \mathrm{~h}$, which corresponds to 276 cycles of reduction and oxidation on average.

The first two days, the solid was circulated with air injection in AR1 and AR2 at $800^{\circ} \mathrm{C}$, and nitrogen in $\mathrm{FR}$ at $850^{\circ} \mathrm{C}$, after which the temperature was increased to $900^{\circ} \mathrm{C}$ in all reactors and methane combustion was started. Some breaks are observable in the circulation of the solid and combustion of methane (Figure 3), due to experimental circumstances. Indeed, the solid loss at the carbon stripper and the cyclones was not negligible during the test. During the week-end, the circulation of the solid could have stopped if too much material were to be lost. Thus, it was decided to stop the circulation of the material over the week-ends (but fluidization of the solid was maintained at $800^{\circ} \mathrm{C}$ ). Some small breaks also occurred during the week, due to the apparition of circulation issues which were quickly solved. After almost 160h of operation, the test had to be stopped since the particle quantity was below minimum operational level due to the losses over time. 
The quantity of oxygen released by the material is represented by the $\mathrm{R} \Delta \mathrm{X}$ value, where $\Delta \mathrm{X}$ corresponds to the conversion of the oxygen carrier in the fuel reactor and $\mathrm{R}_{0}$ corresponds to the oxygen transfer capacity of the fresh material :

$$
R_{0}=\frac{m_{\text {Oavailable }}}{m_{\text {solid }}}=\frac{\frac{m_{C u}}{M_{C u}} M_{O}}{m_{\text {solid }}}=\frac{x_{C u}}{M_{C u}} M_{O}
$$

With $x_{C u}$ corresponding to the copper fraction in the material (wt \%) and $M_{j}$ to the molecular weight of component $j\left(\mathrm{~g} \mathrm{~mol}^{-1}\right)$.

The oxygen transfer capacity of the copper oxide material used in this study $\left(\mathrm{R}_{0}=2.99 \mathrm{wt} \%\right)$ was measured by TGA cycling and corresponds well with the theoretical oxygen transfer capacity of $15 \mathrm{wt} \% \mathrm{CuO} / \mathrm{Al}_{2} \mathrm{O}_{3}$ particles.

The $\mathrm{R}_{0} \Delta \mathrm{X}$ parameter can be calculated in two different ways if the oxygen mass balance is performed on the fuel or the oxygen reactors according to the following equations.

$$
\begin{gathered}
R_{0} \Delta X_{F R}=\frac{\left(\int_{t_{0}}^{t_{f}}\left(2 F_{C O_{2}}^{F R}+F_{C O}^{F R}\right) d t+\frac{m_{H_{2} O}^{\text {condenser }}}{M_{H_{2} O}}\right) M_{O}}{\int_{t_{0}}^{t_{f}} Q_{m, s} d t} \\
R_{0} \Delta X_{A R}=\frac{\left(\int_{t_{0}}^{t_{f}}\left(2 F_{O_{2}, \text { in }}^{A R 1}+2 F_{O_{2}, \text { in }}^{A R 2}-2 F_{C O_{2}}^{A R 1}-F_{C O}^{A R 1}-2 F_{O_{2}}^{A R 1}-2 F_{O_{2}}^{A R 2}\right) d t\right) M_{O}}{\int_{t_{0}}^{t_{f}} Q_{m, s} d t}
\end{gathered}
$$

with $t_{f}-t_{0}$ standing for the duration of the mass balance $(\mathrm{s}), F_{j}^{i}$ the molar flow rate of component $j$ at the outlet of reactor $i\left(\mathrm{~mol} \mathrm{~s}^{-1}\right), m_{\mathrm{H}_{2} \mathrm{O}}^{\text {condenser }}$ the mass of water obtained at the condenser of the fuel reactor during the duration of the mass balance $(\mathrm{kg})$ and $Q_{m, s}$ the solid flow rate $\left(\mathrm{kg} \mathrm{s}^{-1}\right)$.

The values of $R_{0} \Delta X_{F R}$ and $R_{0} \Delta X_{A R}$ are similar for each mass balance, and the values of $R_{0} \Delta X$ presented in Figure 2 correspond to the average between these two $R_{0} \Delta X_{j}$ values. 


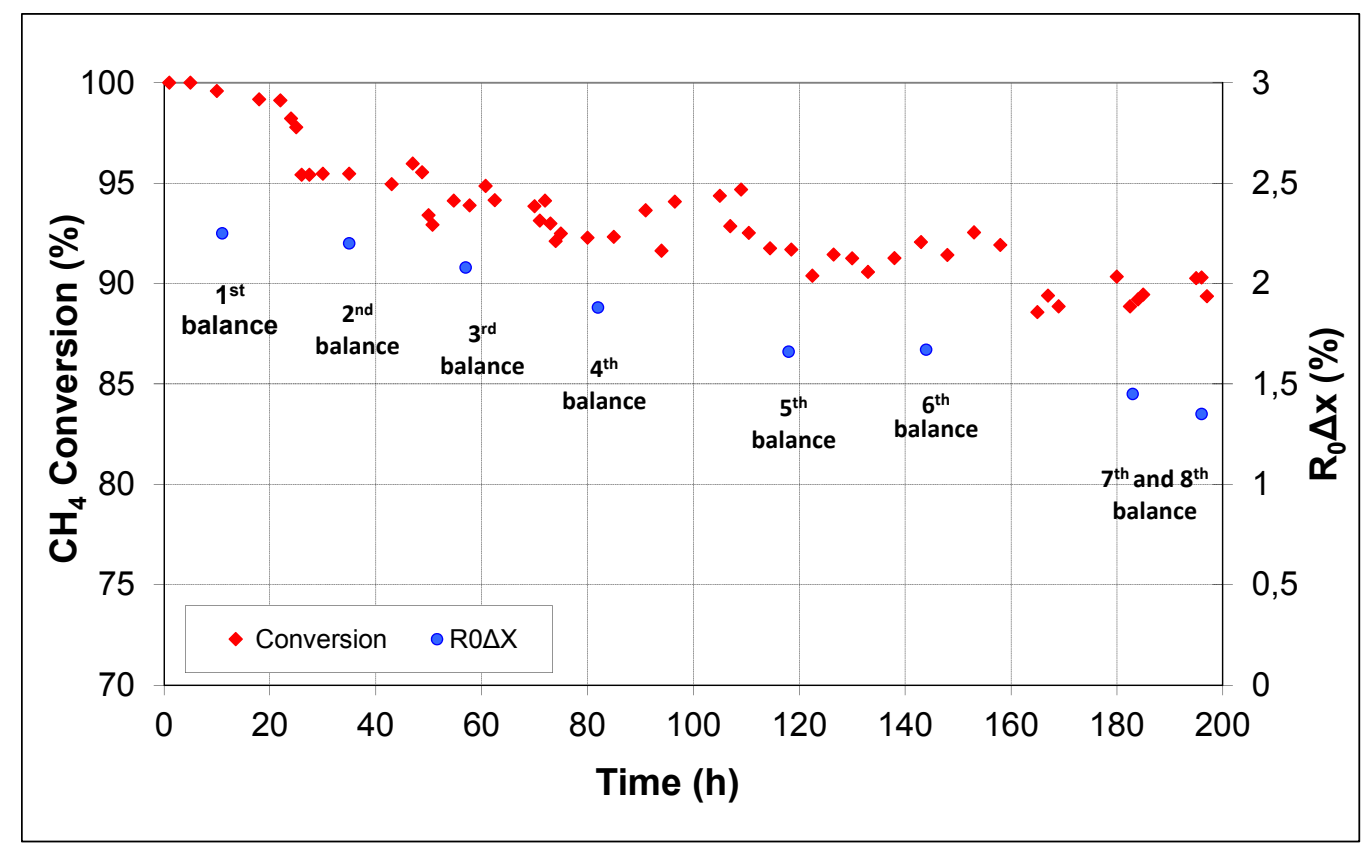

Figure 2 : Methane conversion and $R_{0} \Delta X$ as a function of combustion time

Figure 3 shows that at the beginning of combustion, the conversion of methane to water and carbon dioxide was close to $100 \%$. As time increased, the conversion of methane decreased and the production of hydrogen and carbon monoxide increased, at the expense of carbon dioxide. This indicates that the material's reactivity decreases with time, and partial oxidation occurs even though the residence time of the solid and the gas phase are kept constant. This decline of reactivity is confirmed by the decreasing values of $\mathrm{R}_{0} \Delta \mathrm{X}$ with time, which means that the quantity of oxygen transferred from the $\mathrm{OC}$ to the fuel decreases with time. 


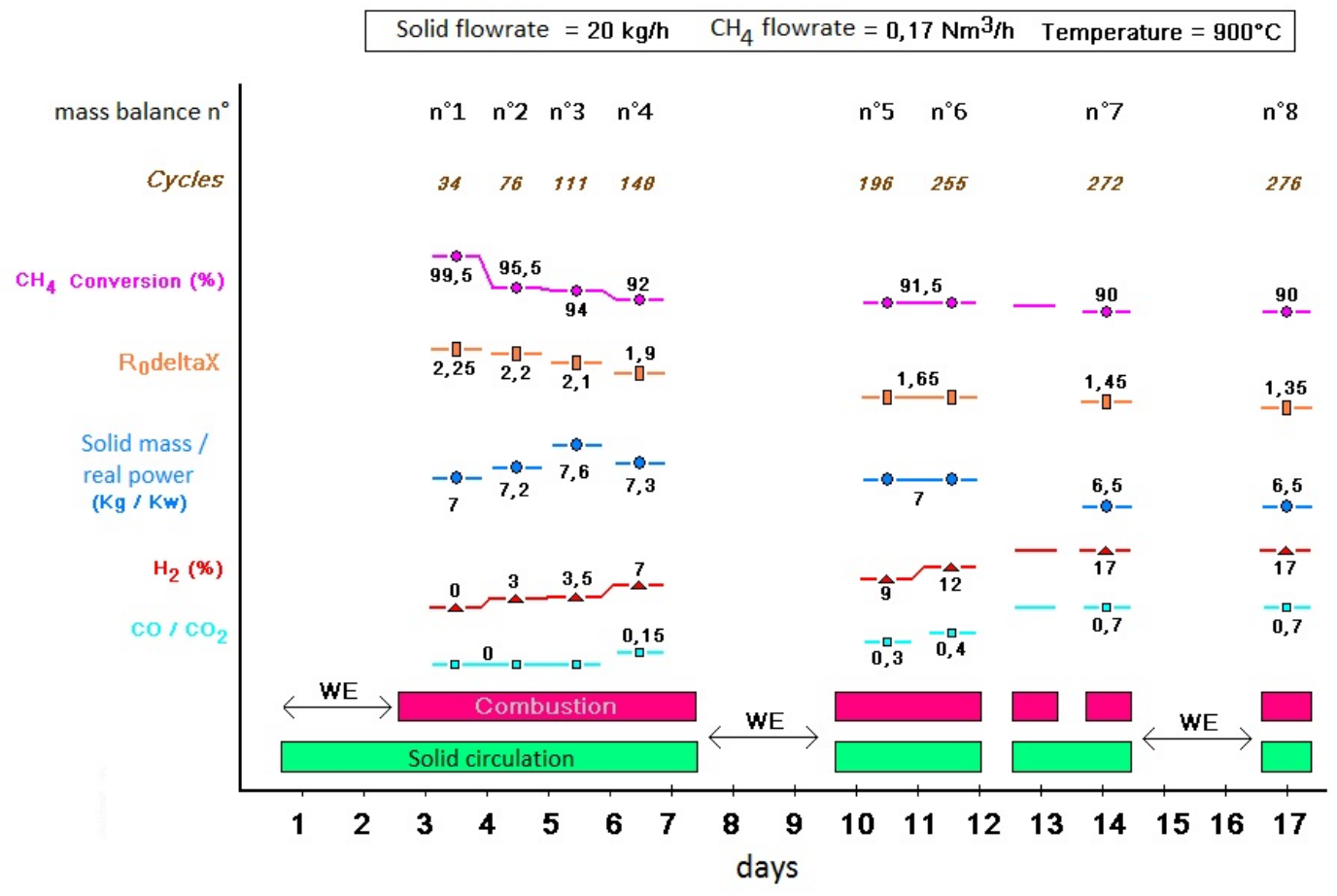

Figure 3. Summary of the experimental results

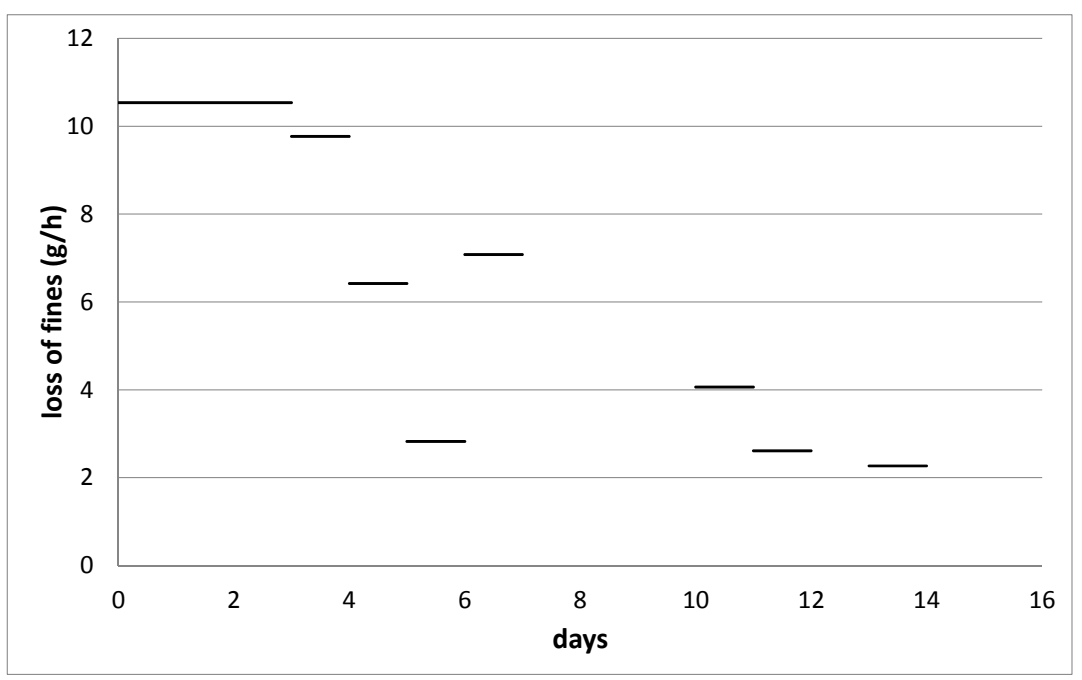

Figure 4 : loss of fines during the ageing experiment

The loss of fines is rather high at the beginning of the ageing experiment $(10.5 \mathrm{~g} / \mathrm{h}$, with about $18 \mathrm{~kg}$ OC in the unit), and it decreases and tends to stabilize at $2.3 \mathrm{~g} / \mathrm{h}$ (Figure 4 , with $16.7 \mathrm{~kg}$ OC remaining in the unit). These loss of fines values are calculated from the quantity of particles with diameters below $100 \mu \mathrm{m}$ gathered at the outlets of the unit at different ageing times, e.g. 100 grams of particles lost during 10 hours lead to a loss of fines of $10 \mathrm{~g} / \mathrm{h}$. If the 
loss of fines stabilizes at $2.3 \mathrm{~g} / \mathrm{h}$, an expected lifetime of $7200 \mathrm{~h}$ (i.e. $\sim 11000$ redox cycles) can be calculated based on $16.7 \mathrm{~kg}$ of particles remaining in the unit at that point.

Cabello et al. have reported a sudden increase of the attrition rate in their $500 \mathrm{~W}_{\text {th }}$ pilot unit after about $50 \mathrm{~h}$ methane combustion at $900^{\circ} \mathrm{C} .{ }^{9}$ The very promising particle lifetime calculated from the ageing experiment in IFPEN's $10 \mathrm{~kW}_{\text {th }}$ unit is therefore to be considered with caution, since the test had to be stopped after a relatively low number of cycles, especially when looking at the results of aged particles characterization.

\subsection{Particles' characterization}

All the analyzed samples were collected in their oxidized form from the cyclone of AR2, except for the very fine particles, which were collected at the filter candle after the cyclone.

\subsubsection{XRD}

The X-Ray Diffractograms of the oxygen carrier particles with increasing cycling time are shown in Figure 5. In the fresh $\mathrm{OC}$, only copper oxide $(\mathrm{CuO})$ and $\gamma$-alumina $\left(\gamma-\mathrm{Al}_{2} \mathrm{O}_{3}\right)$ were detected (not shown). After 34 cycles ( 1 day of combustion), no more $\gamma-\mathrm{Al}_{2} \mathrm{O}_{3}$ is detected, but a spinel phase $\left(\mathrm{CuAl}_{2} \mathrm{O}_{4}\right)$ containing most of the copper has formed, while the signal for copper oxide $(\mathrm{CuO})$ is rather low. $\delta-\mathrm{Al}_{2} \mathrm{O}_{3}$, a transition alumina, is also detected, as well as $\alpha-\mathrm{Al}_{2} \mathrm{O}_{3}$, which is the thermodynamically stable form of alumina.

To visualize the evolution of the various phases, the area of chosen XRD peaks representative of the various phases $\left(\alpha-\mathrm{Al}_{2} \mathrm{O}_{3}: 42.5^{\circ} 2 \theta, \mathrm{CuAl}_{2} \mathrm{O}_{4}: 44.8^{\circ} 2 \theta, \delta-\mathrm{Al}_{2} \mathrm{O}_{3}: 45.5^{\circ} 2 \theta, \mathrm{CuO}: 48.1^{\circ} 2 \theta\right)$ were measured in the aged samples and normalized to 1 with regards to their highest area (Figure 6). As the number of cycles increases, the amount of spinel and $\delta-\mathrm{Al}_{2} \mathrm{O}_{3}$ present in the particles decreases, while more $\alpha-\mathrm{Al}_{2} \mathrm{O}_{3}$ and copper oxide are detected. At the end of the ageing experience, the particles are constituted mainly of $\alpha-\mathrm{Al}_{2} \mathrm{O}_{3}$ and copper oxide, with some $\mathrm{CuAl}_{2} \mathrm{O}_{4}$ spinel still detected, but no more $\delta-\mathrm{Al}_{2} \mathrm{O}_{3}$. 


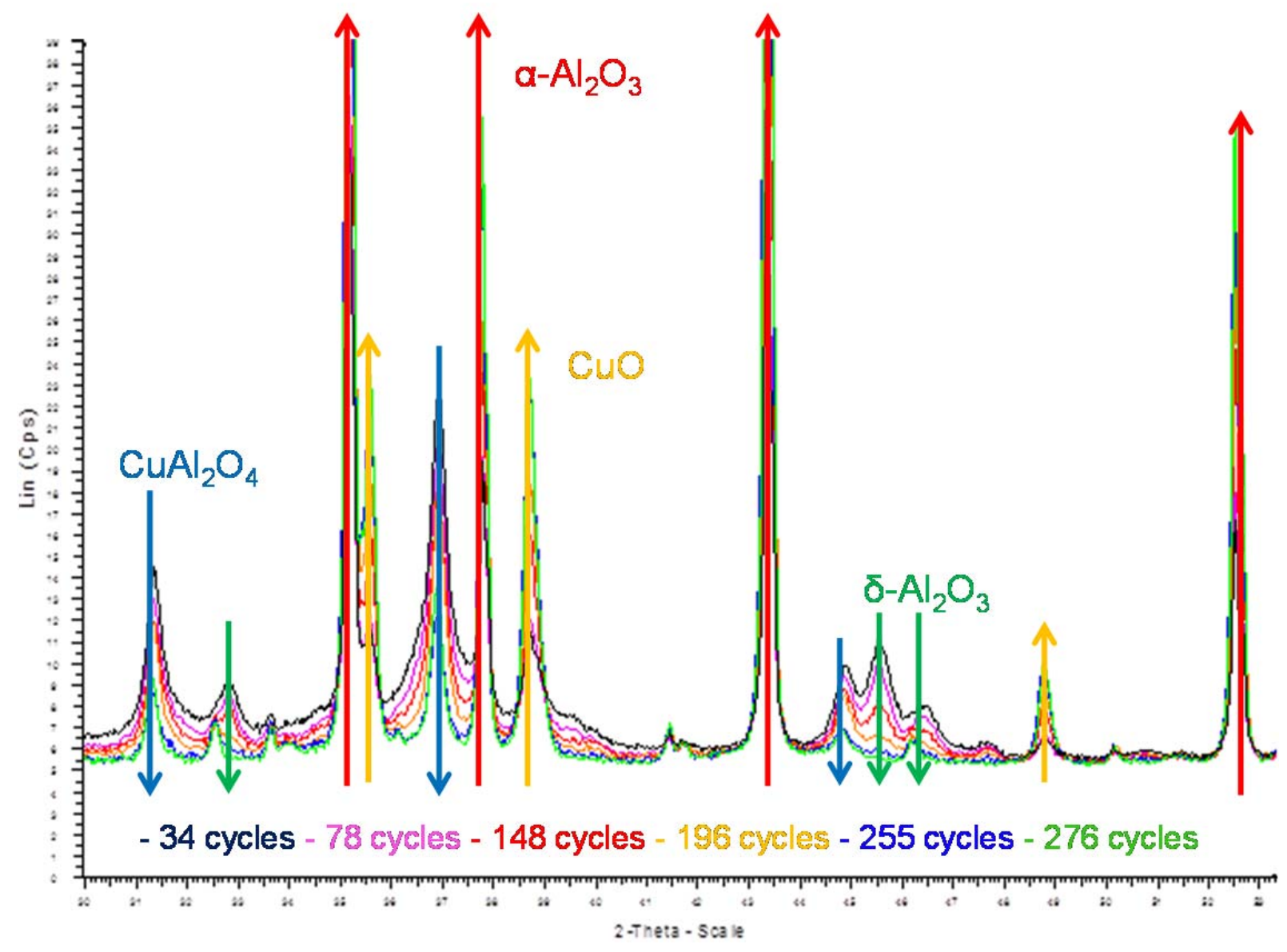

Figure 5 : X-Ray Diffractograms of oxygen carrying particles as a function of number of redox cycles 


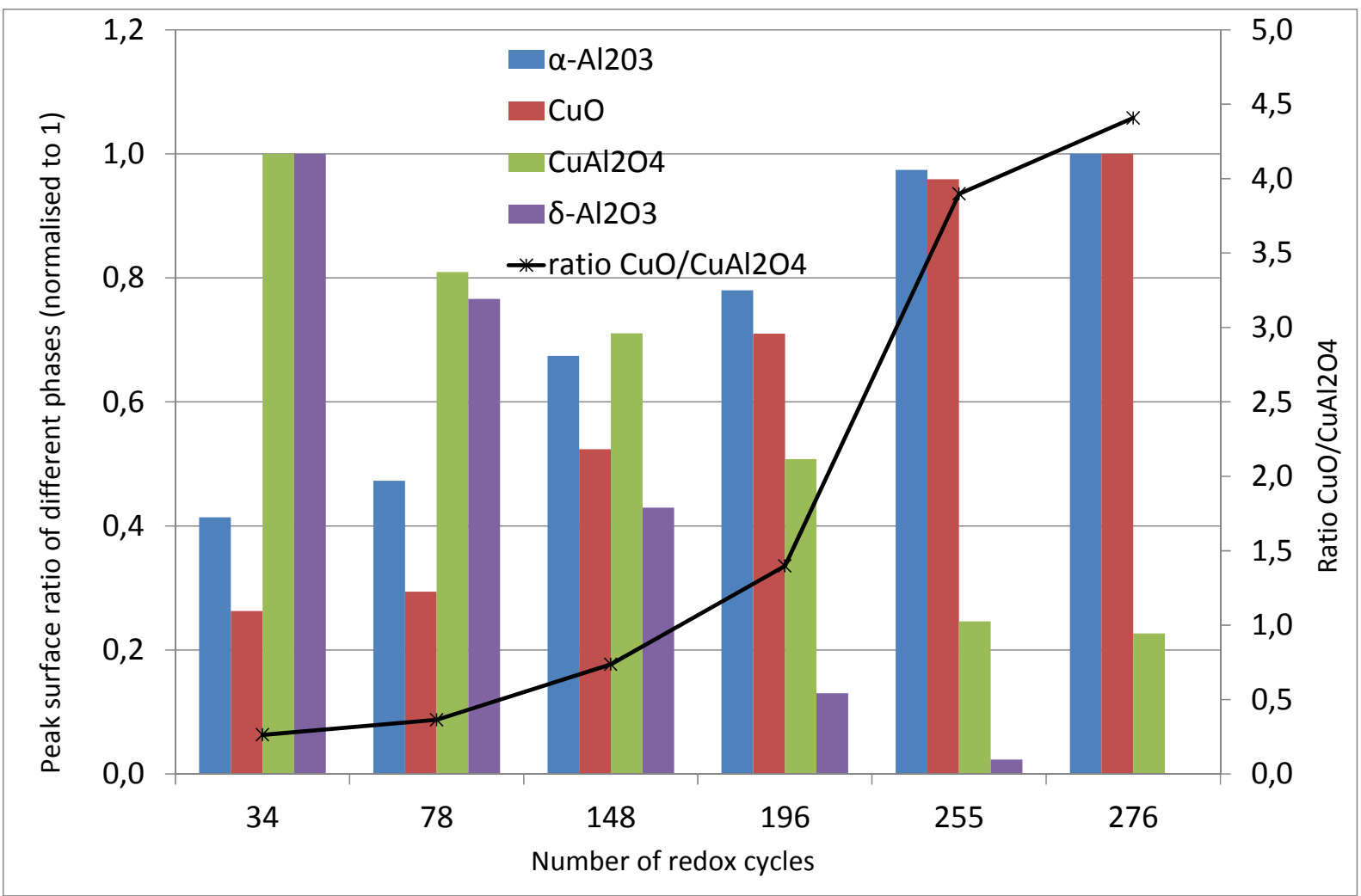

Figure 6 : Peak surface area ratio of the different crystallographic phases measured by XRD at different ageing stages. The ratio for each phase has been normalized to 1.

\subsubsection{SEM analysis}
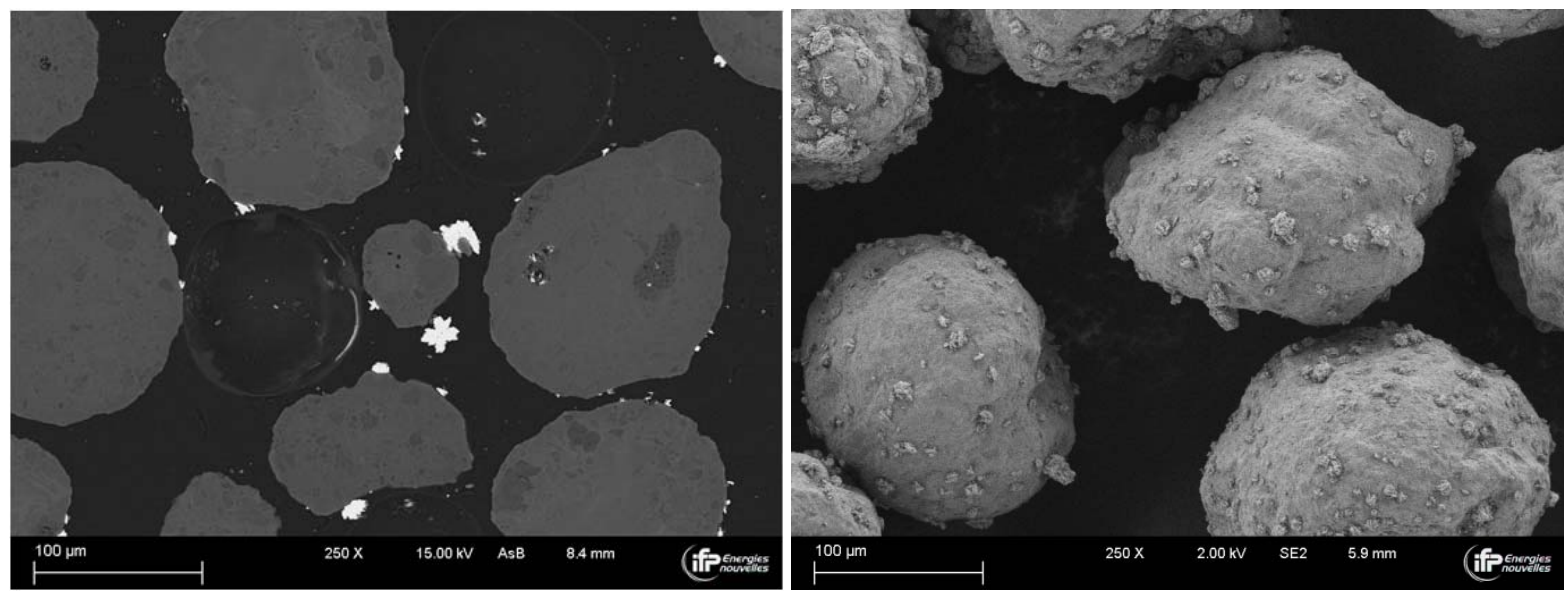

Figure 7: cross-cut section (left) and powder (right) SEM analysis of fresh particles

SEM analysis of fresh particles (Figure 7) shows that some of the copper is present as small $\mathrm{CuO}$ crystallites on the surface of the particles. SEM-EDX analysis (not shown) however confirms that most copper is present inside the particles and is uniformly dispersed. 
After 34 cycles, most of the copper initially present as external $\mathrm{CuO}$ particles has disappeared (Figure 8). This is probably due to attrition caused by fluidization, eliminating small surface copper particles as fines. This is supported by the very high $\mathrm{Cu}$ content of the fines collected at the filter candle (vide infra, section 3.2.4).

SEM pictures also show that the texture of the particles has changed drastically, going from a homogeneous porosity and copper distribution to a core/shell type structure, with a dense looking core containing copper-rich nodules and a more porous outer shell containing no copper at all, as established by SEM-EDX pictures (Figure 9). The morphology of this porous copper free corolla resembles that of macroporous $\alpha-\mathrm{Al}_{2} \mathrm{O}_{3}$ and its thickness varies between 5 and $10 \mu \mathrm{m}$. Some of the copper is still rather well dispersed within the core, and some of it tends to segregate at the interface between the core and the macroporous shell. In a few particles, cracks are observed, mainly in the vicinity of the copper-rich nodules (Figure 8).

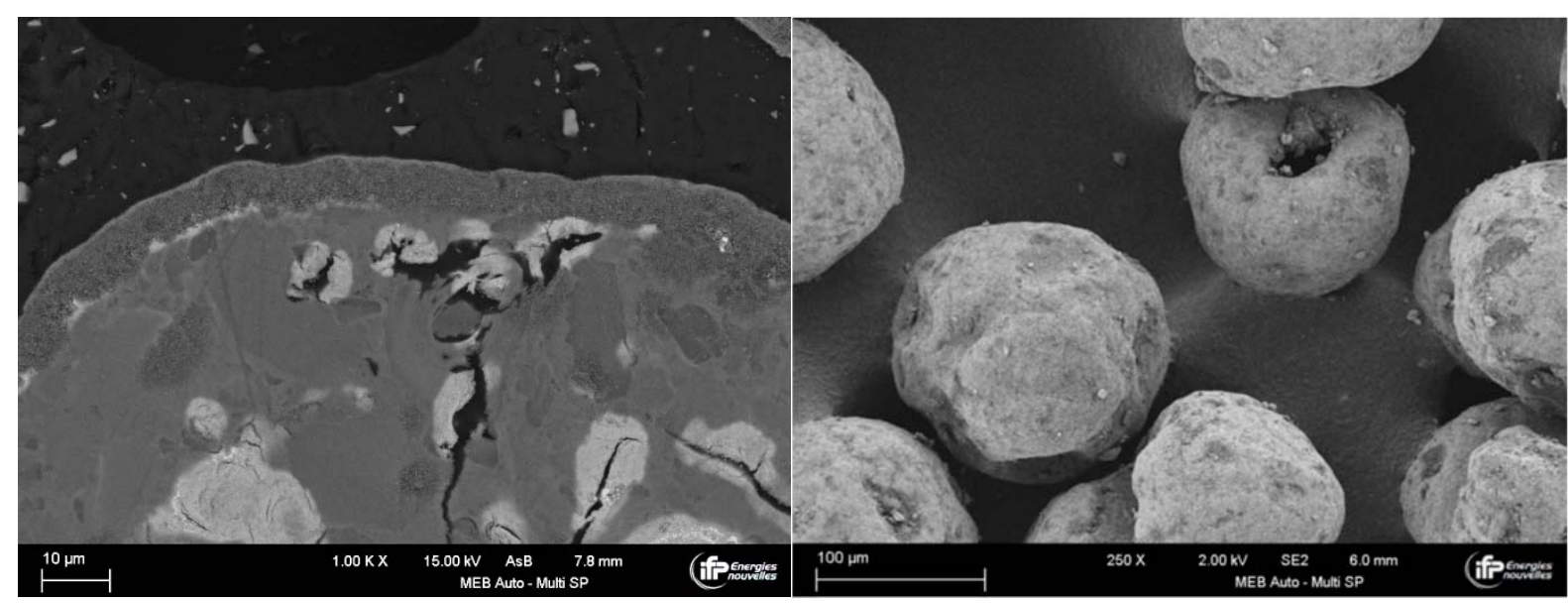

Figure 8 : cross-cut section (left) and powder (right) SEM analysis of particles after 34 cycles 


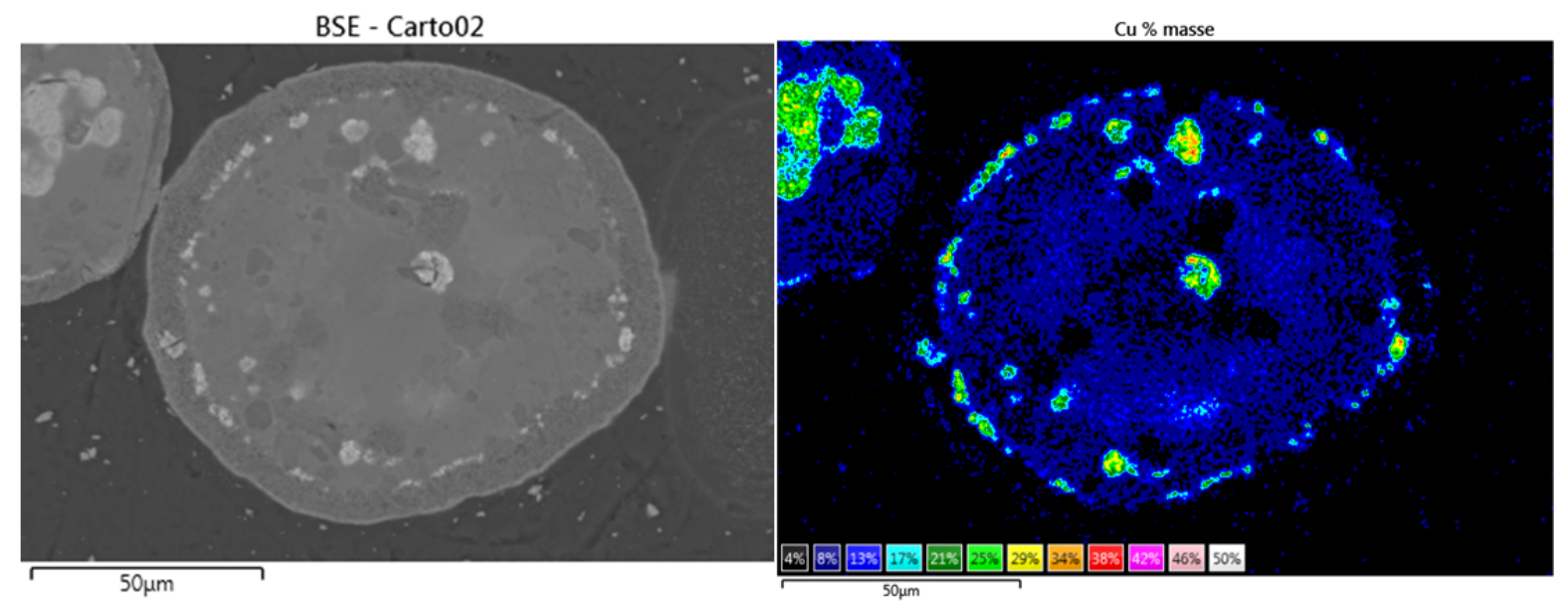

Figure 9 : Quantitative X-Ray map of particles after 34 cycles

After 148 cycles, the macroporous corolla is still observed, with a similar thickness, but unlike in the previous sample, some $\mathrm{Cu}$ is located at the outer surface of a few particles (Figure 10). A macroporous structure similar to that of the corolla has developed inside the inner core, and $\mathrm{Cu}$ is less dispersed than previously, with larger, more numerous copper-rich nodules. More cracking is also observed. After 255 and 276 cycles, the extent of cracking has increased even more, and the particles are made up mainly by the macroporous structure and poorly dispersed copper (Figure 11). A denser looking phase is also present, appearing in light gray in the SEM pictures and which contains both $\mathrm{Cu}$ and $\mathrm{Al}$.
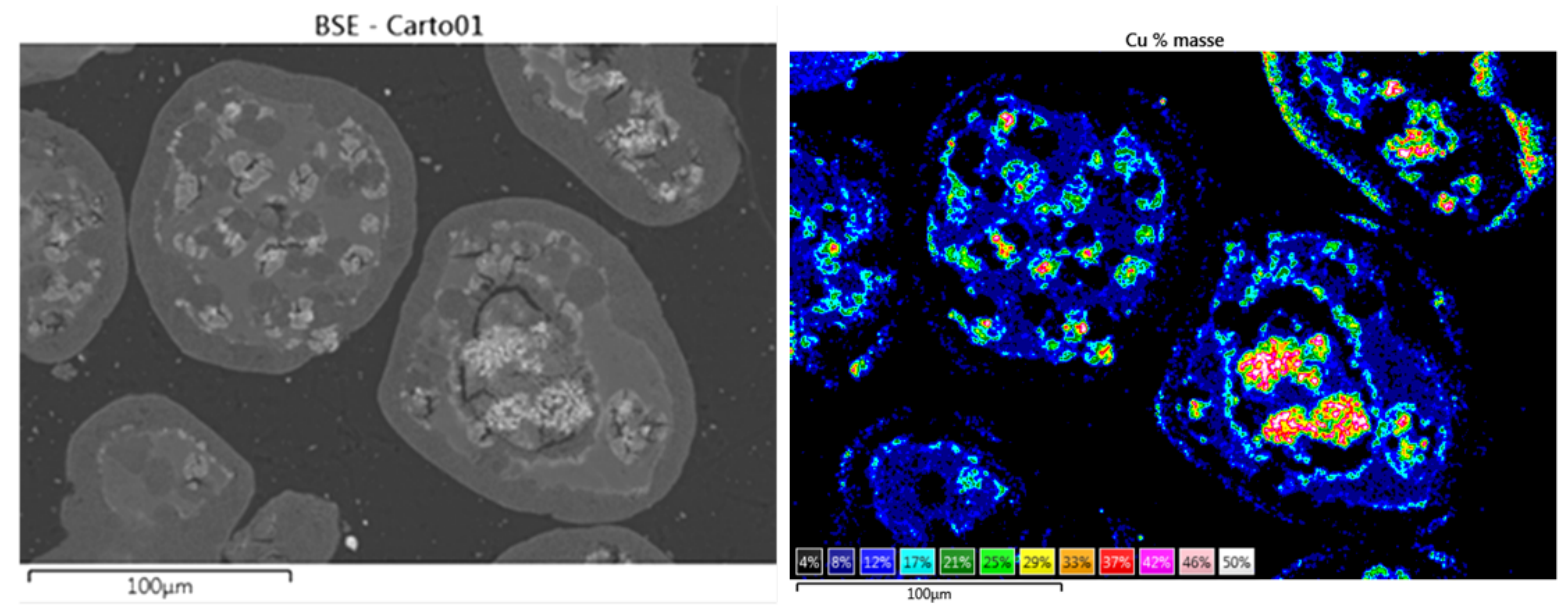

Figure 10: Quantitative X-Ray map of particles after 148 cycles 
Interestingly, none of the cracks could be observed debouching at the surface of the particles in direct powder SEM observation (not shown), and the presence of copper at the surface of the particles that can be seen in Figure 11 was confirmed by direct powder observation.

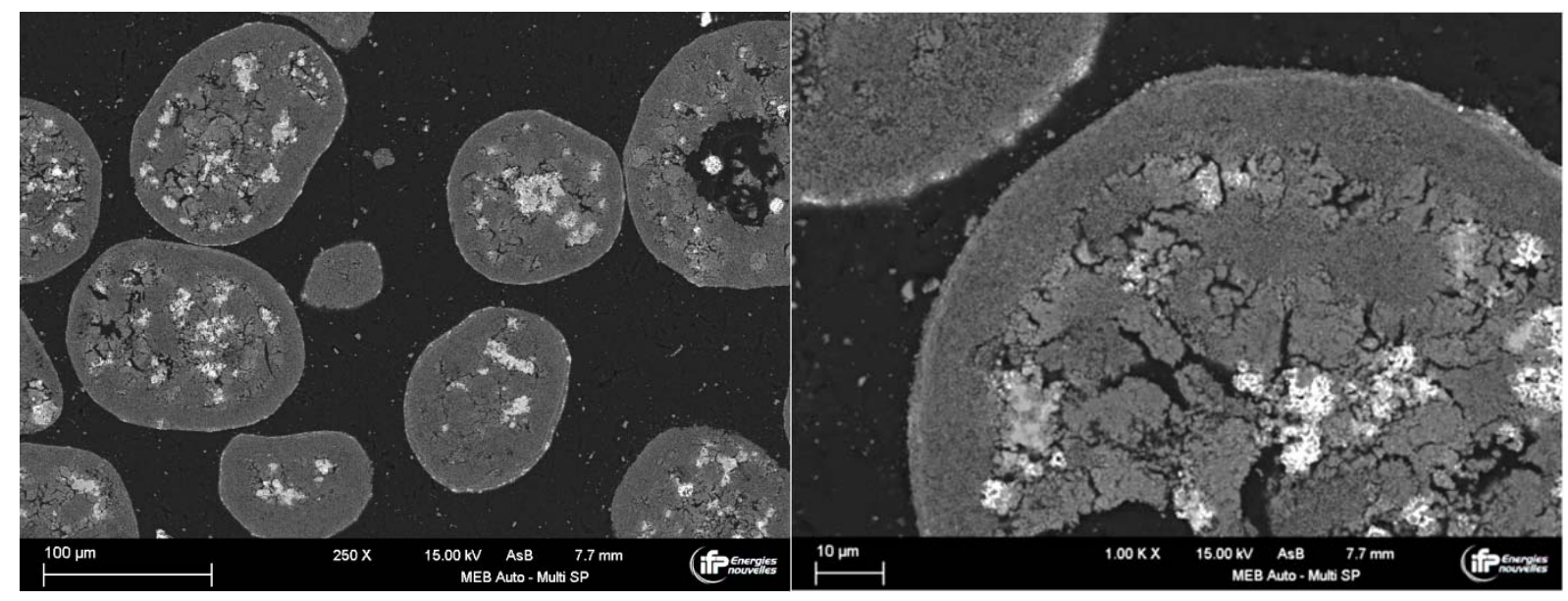

Figure 11: cross-cut section SEM analysis of particles after 276 cycles

Considering both SEM and XRD results, it is qute clear that the macroporous phase which forms gradually as the number of cycles increases is the thermodynamically stable $\alpha-\mathrm{Al}_{2} \mathrm{O}_{3}$ phase, that the light gray areas are made of $\mathrm{CuAl}_{2} \mathrm{O}_{4}$, and that the bright white areas are made of $\mathrm{CuO}$.

Cabello et al. also used SEM to characterize their used particles after $65 \mathrm{~h} \mathrm{CLC}$ at $900^{\circ} \mathrm{C}$, during which the OC/fuel ratio was varied with time. ${ }^{9}$ They observed a strong cracking of the used particles, but do not mention the presence of an outer $\alpha-\mathrm{Al}_{2} \mathrm{O}_{3}$ shell. After $60 \mathrm{~h}$ methane combustion at $800^{\circ} \mathrm{C}$, they observed copper nodules inside the particles, but no cracks formation.

\subsubsection{Porosity}

The porosity of the OC particles at different ageing stages was measured by mercury porosimetry. Initially, the particles are purely mesoporous, with pore diameters centered around $12 \mathrm{~nm}$ (Figure 12). After 34 cycles, the total porous volume of the particles has decreased from $0.37 \mathrm{ml} / \mathrm{g}$ to $0.28 \mathrm{ml} / \mathrm{g}$, while the pore size distribution has evolved into two 
porosity modes: large mesopores around $30 \mathrm{~nm}$ and macropores around $200 \mathrm{~nm}$. Upon further cycling, the mesopores tend to disappear, while the macropores tend to increase in size (up to 330 $\mathrm{nm}$ ) and volume (up to $0.25 \mathrm{ml} / \mathrm{g}$ ), until reaching a plateau at the end of the test (Figure 13).

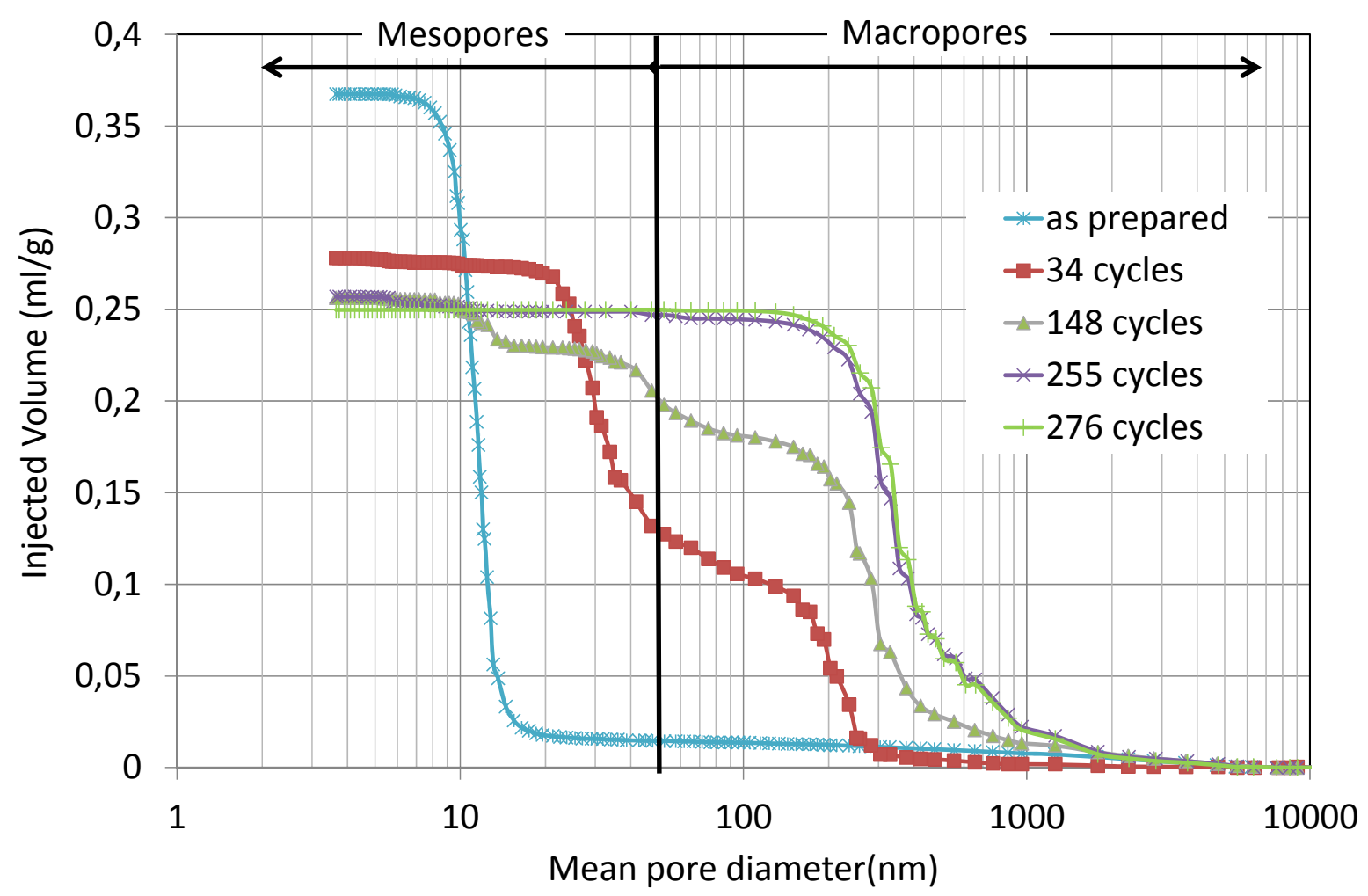

Figure 12: Mercury porograms of fresh and aged oxygen carrying particles after various numbers of cycles 


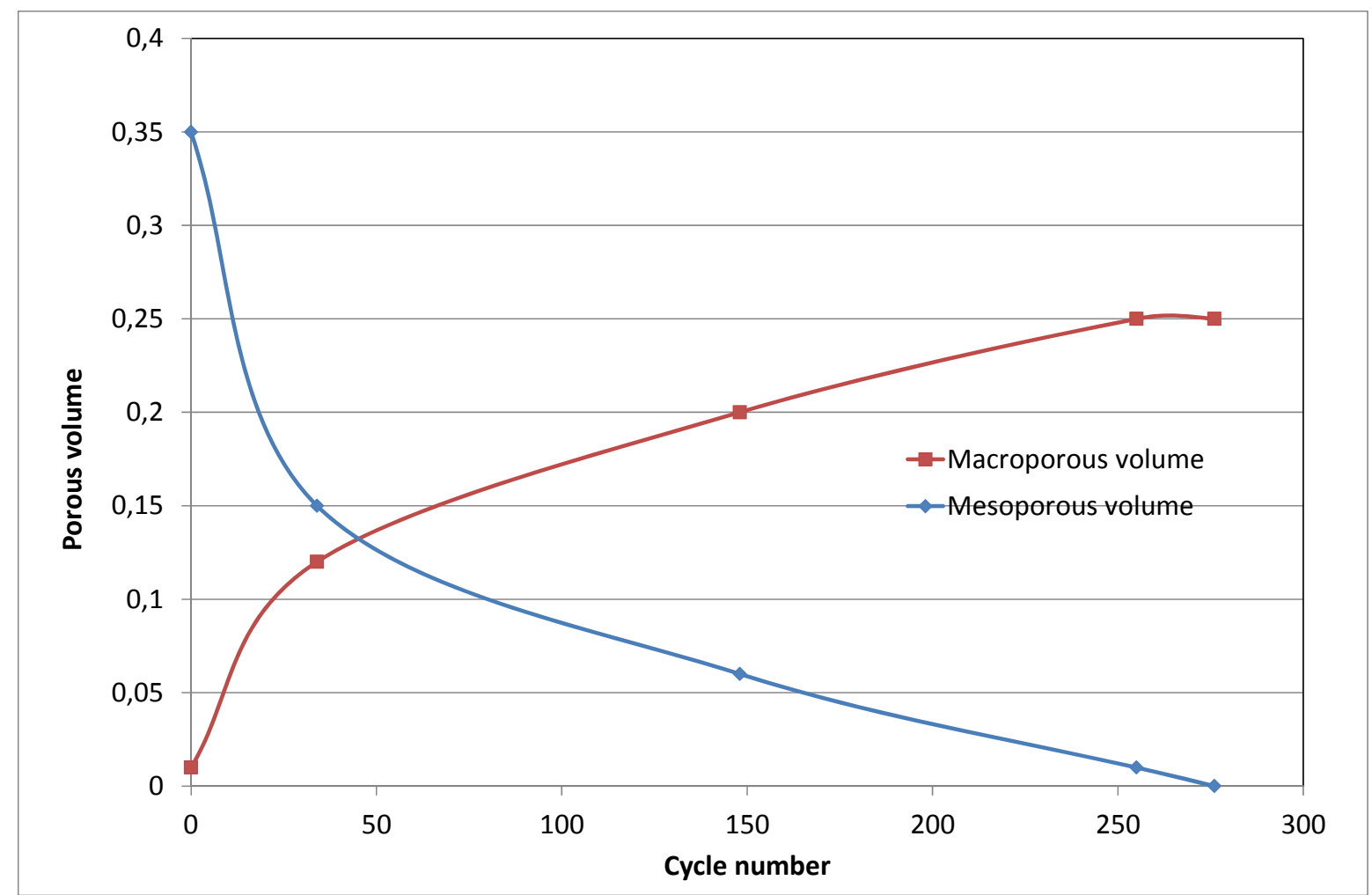

Figure 13 : Macroporous and mesoporous volumes of OC particles as a function of cycle number

When put in perspective with XRD and SEM results, it is likely that the $\alpha-\mathrm{Al}_{2} \mathrm{O}_{3}$ corolla around the particles is responsible for the macroporosity measured after 34 cycles. The rather large associated macroporous volume actually is a measurement of both the porous volume of the corolla layer itself and the volume created by the appearing cracks in the core.

Upon further cycling, the size of the macropores in the corolla increases due to alumina sintering, and so does the porous volume associated to the macroporous phase and the cracks. This is in line with the observation that more of the macroporous $\alpha-\mathrm{Al}_{2} \mathrm{O}_{3}$ phase and more cracks are observed as time increases.

Regarding the mesoporosity, it can be associated initially to the presence of the spinel $\left(\mathrm{CuAl}_{2} \mathrm{O}_{4}\right)$ and/or of $\delta-\mathrm{Al}_{2} \mathrm{O}_{3}$, but it disappears completely at the end of the test, indicating that these phases become less and less porous as cycles go by.

The BET surface area $\left(\mathrm{S}_{\mathrm{BET}}\right)$ of the fresh OC is very high (Table 1). A strong decrease of the surface area is observed after 34 cycles, followed by a slower, steadier decrease upon further 
ageing. There does not seem to be any direct link between the decrease of methane conversion and that of $\mathrm{S}_{\mathrm{BET}}$. Indeed, after 34 cycles, $99.7 \%$ methane conversion to $\mathrm{CO}_{2}$ and water is still observed despite the drastic fall in $\mathrm{S}_{\mathrm{BET}}\left(-112 \mathrm{~m}^{2} / \mathrm{g}\right)$, whereas after 148 cycles, methane conversion is down to $92.6 \%$ for a mere $3.7 \mathrm{~m}^{2} / \mathrm{g}$ fall in $\mathrm{S}_{\mathrm{BET}}$. Adding $\sim 100$ more cycles, the surface area collapses down to $3.3 \mathrm{~m}^{2} / \mathrm{g}$, while methane conversion remains around $90 \%$, albeit with more $\mathrm{CO}$ and $\mathrm{H}_{2}$ production. In the meantime, the amount of oxygen transferred from the $\mathrm{OC}$ to the fuel decreases sharply.

Table $1: B E T$ surface area and $\mathrm{CH}_{4}$ conversion levels of the fresh and aged $\mathrm{OC}$

\begin{tabular}{|l|c|c|c|c|c|}
\hline Cycle $\mathrm{n}^{\circ}$ & 0 & 34 & 148 & 255 & 276 \\
\hline $\mathrm{S}_{\mathrm{BET}}\left(\mathrm{m}^{2} / \mathrm{g}\right)$ & 135 & 22.7 & 19 & 3.3 & 2.4 \\
\hline $\mathrm{CH}_{4}$ conversion & - & 99.7 & 92.6 & 91.6 & 90 \\
\hline $\mathrm{R}_{0} \Delta \mathrm{X}(\%)$ & - & 2.25 & 1.88 & 1.67 & 1.35 \\
\hline
\end{tabular}

\subsubsection{Copper content}

Figure 14 shows that the copper content of the OC particles (measured by XRF) fell rather sharply from $11.9 \mathrm{wt} \%$ (i.e. $14,9 \mathrm{wt} \% \mathrm{CuO}$ ) before test to $9.5 \mathrm{wt} \%$ after 34 cycles, and then stabilized. Such a decrease of copper concentration has also been reported by de Diego et al. during their $100 \mathrm{~h}$ test runs with lab-made particles ${ }^{7}$ and by Cabello et al. with the particles used in this work. $^{9}$

Figure 14 shows that the copper content of the fines collected at the filter candles during the test is very high at the beginning, and tends to decrease to a value slightly above that of the bulk OC. We believe that the large copper loss at the beginning of the test is mainly due to the elimination of the $\mathrm{CuO}$ crystallites observed on the surface of the fresh particles (Figure 7). Besides, the amount of fines collected at the filter candles at the beginning of the test is quite 
high, albeit negligible compared to the amount collected in the carbon stripper and the cyclones, and then reduces significantly. As a consequence, the loss of copper in the fines has a measurable impact on the bulk particles' copper content mainly at the beginning of the test.

It should also be pointed out that most of the solids loss throughout the ageing experiment originates from particles below $100 \mu \mathrm{m}$ in the carbon stripper and the cyclones, and that the $\mathrm{Cu}$ content of these particles is close to that of the bulk particles remaining in the unit (not shown).

Copper migration to the surface of particles has been observed with silica supported copper oxide after 20 redox cycles in fixed bed configuration, ${ }^{12}$ and our SEM results show that such migration also occurs with alumina supported copper oxide. Indeed, while no copper can be seen by SEM at the surface of the OC after 34 cycles, there is always some copper detected at the surface of particles in the samples which were aged for a longer period of time, implying copper migration from the inner core to the surface of the particles during successive redox cycles, which can be wiped off as fines by abrasion. Such copper migration and abrasion might be responsible for the slightly higher copper level measured in the very fine particles at the end of the test, which represents low amounts of copper since the quantity of fines in the filter candles is low. 


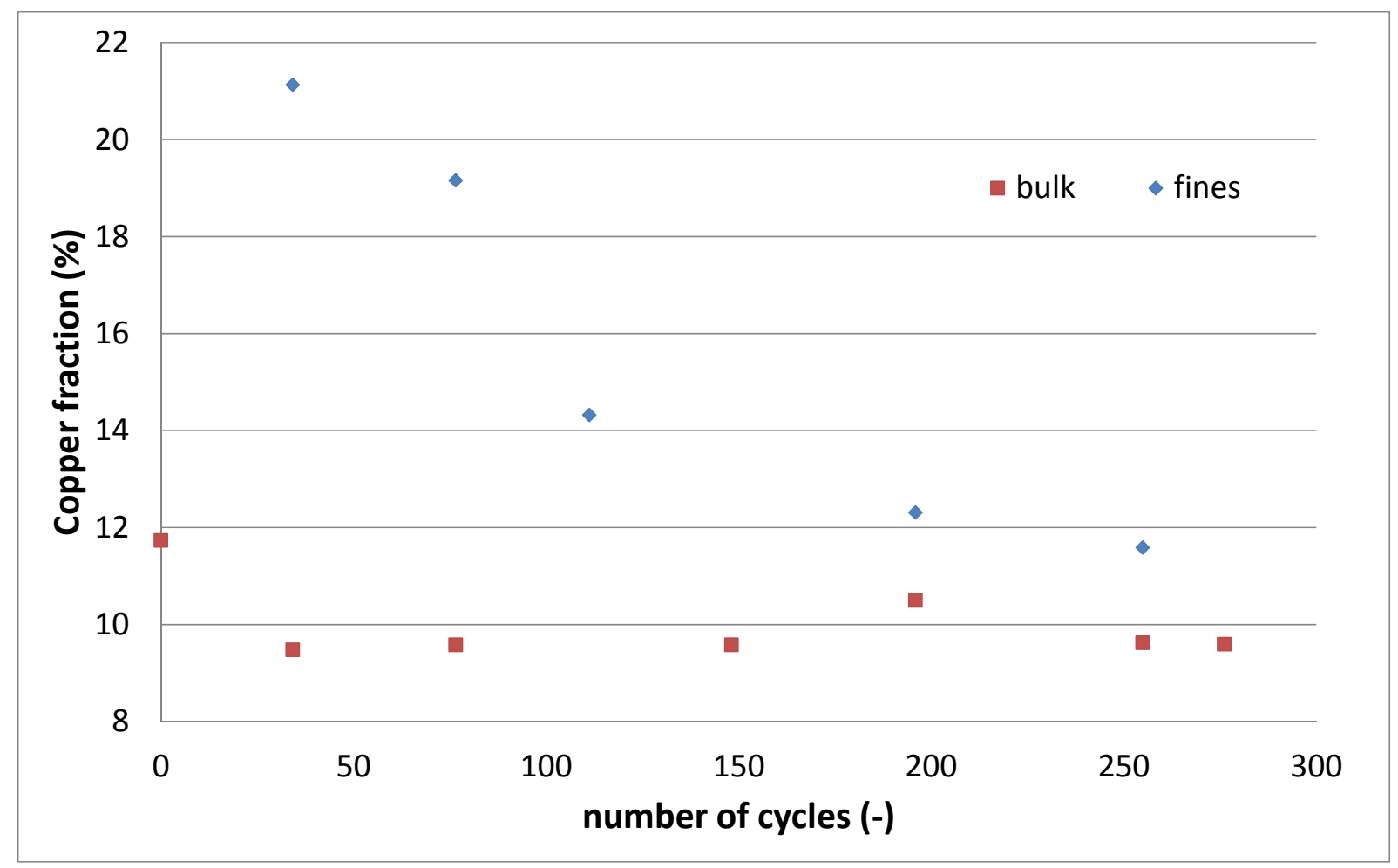

Figure 14 : copper content of $O C$ and fines as a function of cycle number

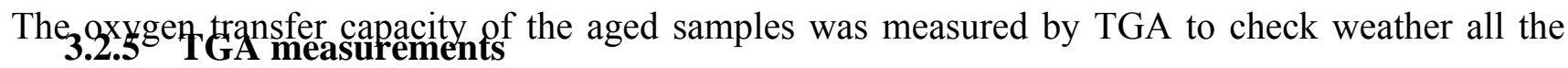
copper (as measured by XRF) in the particles was still able to deliver its oxygen. Figure 15 shows the first 7 cycles obtained with the sample aged for 34 cycles. For all the cycles, the oxygen transfer capacity is $2.3 \%$ (the baseline of the TGA increases slowly during the test, hence the slight shift of the curves with time), which is not very different from the value calculated from the measured copper content $\left(\mathrm{R}_{0} \sim 2.38 \%\right.$ ). The interesting feature here is that the CLOU (Chemical Looping Oxygen Uncoupling) ${ }^{13}$ effect that can be expected from a copper containing OC (reaction (1); $\sim 1.19 \%$ in our case) when switching from air to nitrogen is not very fast, and only a small fraction of copper actually delivers gaseous oxygen upon changing the oxygen partial pressure $\left(\mathrm{R}_{0}\right.$ CLOU $\sim 0.3 \%$ for the first cycle). As the number of TGA cycles increase, so does $\mathrm{R}_{0}$ CLOU $(0.5 \%$ after 10 TGA cycles $)$. 


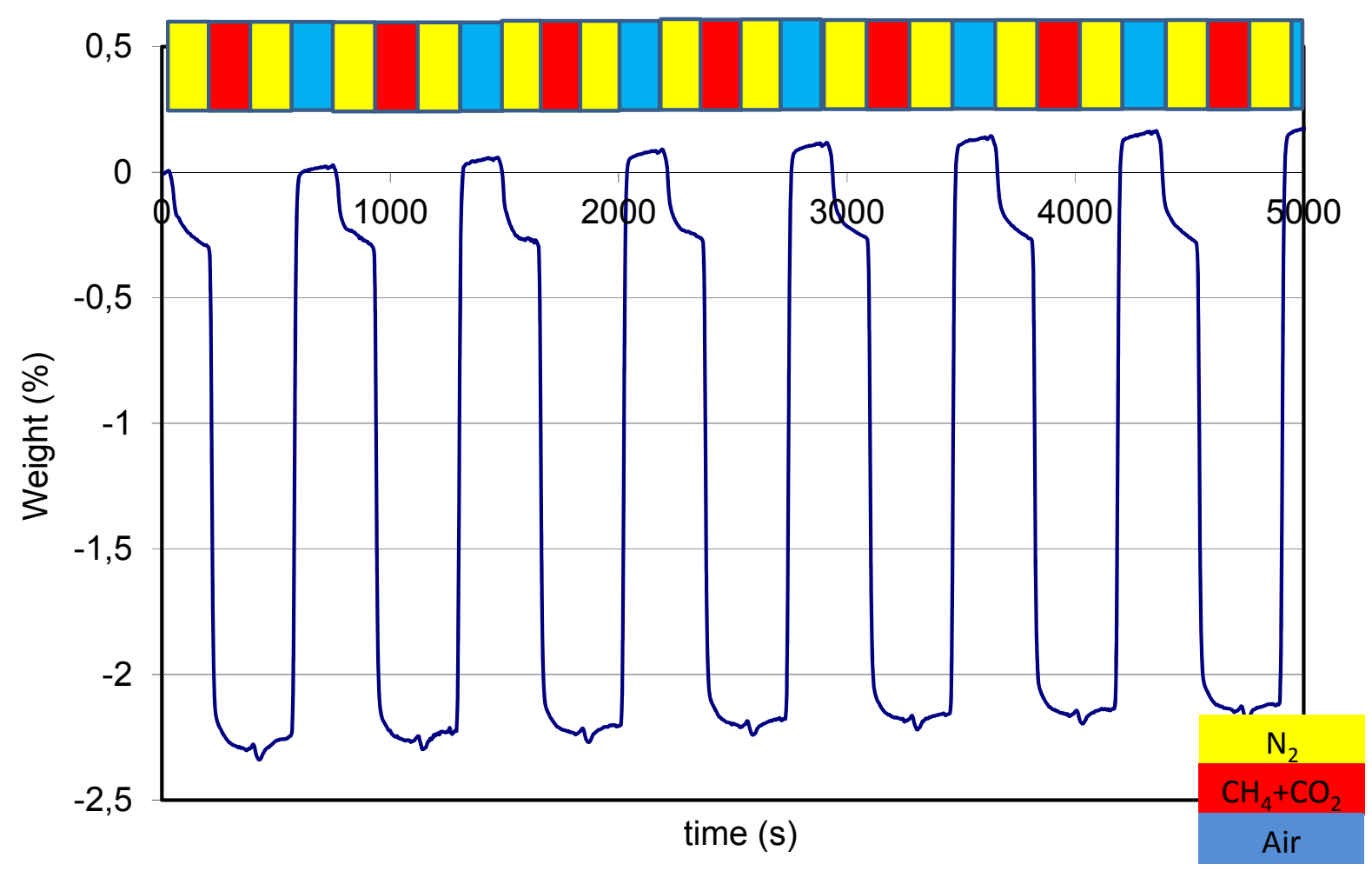

Figure 15 : TGA simulated redox cycles with OC after 34 cycles

Imtiaz et al. studied the $\mathrm{CLOU}$ behavior of $\mathrm{CuO} / \mathrm{Al}_{2} \mathrm{O}_{3}$ oxygen carriers with high $\mathrm{CuO}$ loadings prepared by co-precipitation. ${ }^{14}$ After cycling in a fluidized bed at $950^{\circ} \mathrm{C}$ between air and nitrogen, they showed that $\mathrm{CuAlO}_{2}$ had formed via reaction (2).

$$
\begin{array}{cr}
2 \mathrm{CuO} \rightarrow \mathrm{Cu}_{2} \mathrm{O}+1 / 2 \mathrm{O}_{2} & \text { reaction (1) } \\
4 \mathrm{CuAl}_{2} \mathrm{O}_{4} \rightarrow 4 \mathrm{CuAlO}_{2}+2 \mathrm{Al}_{2} \mathrm{O}_{3}+\mathrm{O}_{2} & \text { reaction (2) }
\end{array}
$$

The same particles were cycled in TGA, showing a rapid decrease of $\mathrm{R}_{0}{ }^{\mathrm{CLOU}}$, and the authors concluded that the decomposition of $\mathrm{CuAl}_{2} \mathrm{O}_{4}$ into $\mathrm{CuAlO}_{2}$ was irreversible under $\mathrm{CLOU}$ conditions. Mei et al. came to the same conclusion with $\mathrm{CuO} / \mathrm{Al}_{2} \mathrm{O}_{3}$ particles prepared by the solgel route, ${ }^{15}$ and they showed that oxygen evolution occurred first by the fast decomposition of $\mathrm{CuO}$ to $\mathrm{Cu}_{2} \mathrm{O}$, followed by the slow decomposition of $\mathrm{CuAl}_{2} \mathrm{O}_{4}$ to $\mathrm{CuAlO}_{2}$.

Looking closely at the weight loss via CLOU effect in Figure 15 (during $\mathrm{N}_{2}$ sweep), both reduction steps are observed with the aged particles : a first, fast reduction of $\mathrm{CuO}$ into $\mathrm{Cu}_{2} \mathrm{O}$, followed by the slower decomposition of $\mathrm{CuAl}_{2} \mathrm{O}_{4}$ to $\mathrm{CuAlO}_{2}$. When switching to the 
reducing gas, $\mathrm{CuAl}_{2} \mathrm{O}_{4}$ 's reduction rate increases, and full reduction of the $\mathrm{OC}$ is quickly achieved, which means that $\mathrm{CuAlO}_{2}$ is reduced by methane. Interestingly, full and fast reoxidation in air is observed, implying that $\mathrm{CuAlO}_{2}$ is probably not part of the reoxidation pathway.

As can be seen in Figure 15, the weight loss at the beginning of the $\mathrm{N}_{2}$ sweeps, due to the reduction of $\mathrm{CuO}$ into $\mathrm{Cu}_{2} \mathrm{O}$, increases slightly from one cycle to the next : this means that more $\mathrm{CuO}$ is present after each reduction/oxidation cycle, which is coherent with the progressive buildup of $\mathrm{CuO}$ and decrease of $\mathrm{CuAl}_{2} \mathrm{O}_{4}$ in the aged particles measured by XRD 394 (c.f. 3.2.1).

The same behavior is observed with the other aged samples, with $\mathrm{R}_{0}$ 's corresponding to the amount of copper in the OC, but the amount of oxygen released by the CLOU effect during the first TGA cycle increases with the number of cycles the sample has been through (Figure 16). This is in line with the observed increase of free $\mathrm{CuO}$ content in the particles with ageing time, since the CLOU effect measured by TGA is limited by the $\mathrm{N}_{2}$ sweep duration and reaction (1) is much faster than reaction (2).

We used the weight loss due to the fast reduction of $\mathrm{CuO}$ into $\mathrm{Cu}_{2} \mathrm{O}$ during the first TGA cycle to estimate the amount of free $\mathrm{CuO}$ for each aged sample (Figure 16). According to this measurement method, the aged particles after 276 cycles contain $9.1 \mathrm{wt} \%$ of free $\mathrm{CuO}$, which represents $\sim 75 \%$ of the total copper oxide content at that stage, consistent with XRD results. 


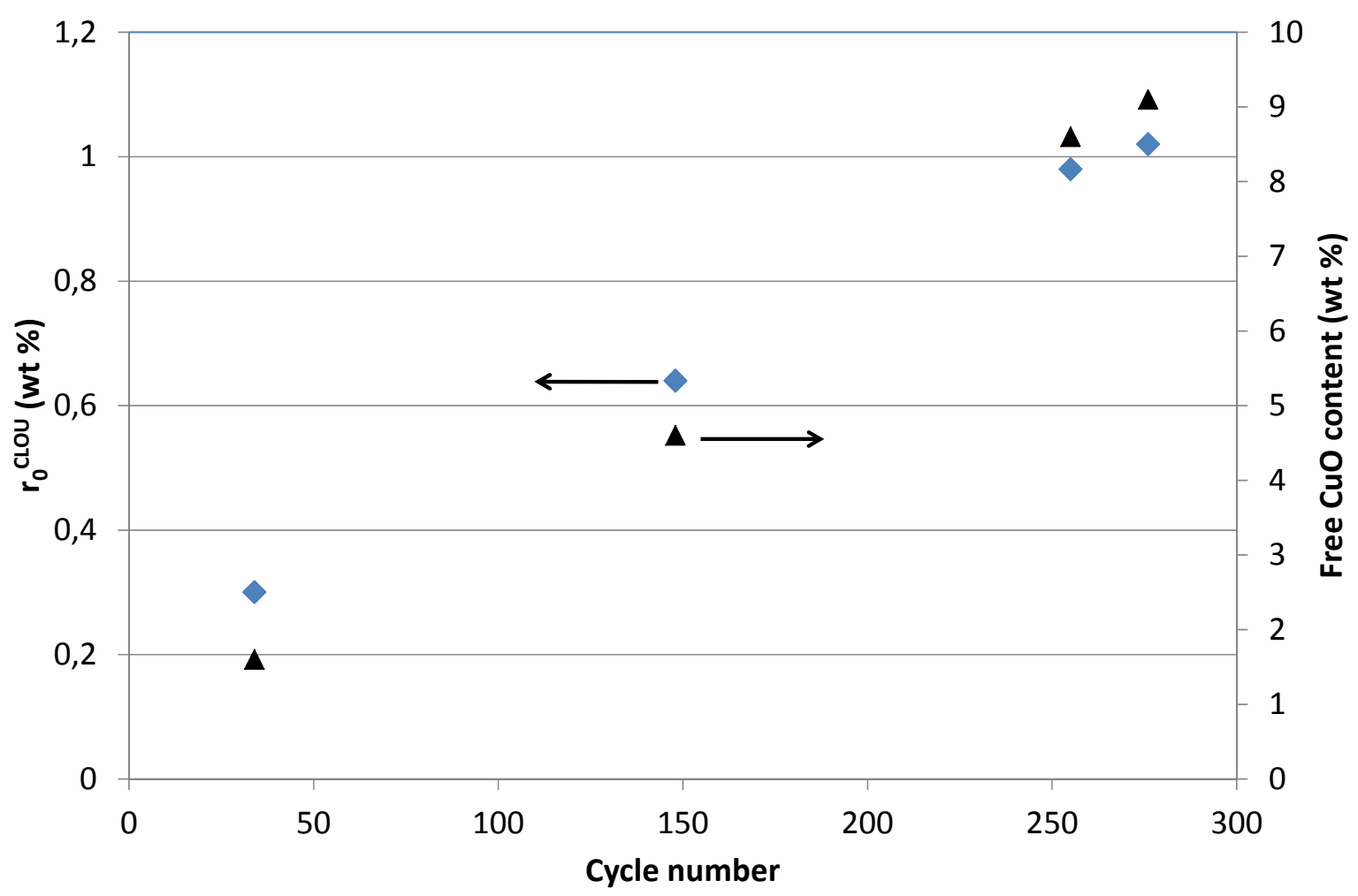

Figure 16: oxygen released by the CLOU effect during the first TGA cycle as a function of ageing test cycle number ( $\bullet$, and calculated free CuO content ( $\mathbf{\Delta})$

While our TGA setup does not allow for accurate reaction rate measurements due to mass transfer limitations, ${ }^{16}$ it can be used to compare the apparent reaction rates of samples tested under the same conditions. Figure 17 shows the instantaneous apparent reaction rates of the aged particles during the $\mathrm{N}_{2}$ sweep period (CLOU effect) and during reducing gas injection. This clearly shows that the OC's reduction rate via CLOU effect increases with the number of cycles, which can be assigned to the increasing amount of free $\mathrm{CuO}$. Meanwhile the OC's reduction rate by methane decreases with increasing number of cycles. The reaction rates after 255 and 276 cycles are very similar regarding CLOU effect and perfectly superposed during reduction by methane, indicating stable reactivity after some point, which is confirmed by methane conversion and $\mathrm{CO} /$ $\mathrm{H}_{2}$ levels produced at the end of the test (Figure 3). It is also 
interesting to notice that the maximum apparent reaction rate during the CLOU effect is far smaller than that due to the OC's reduction by methane.
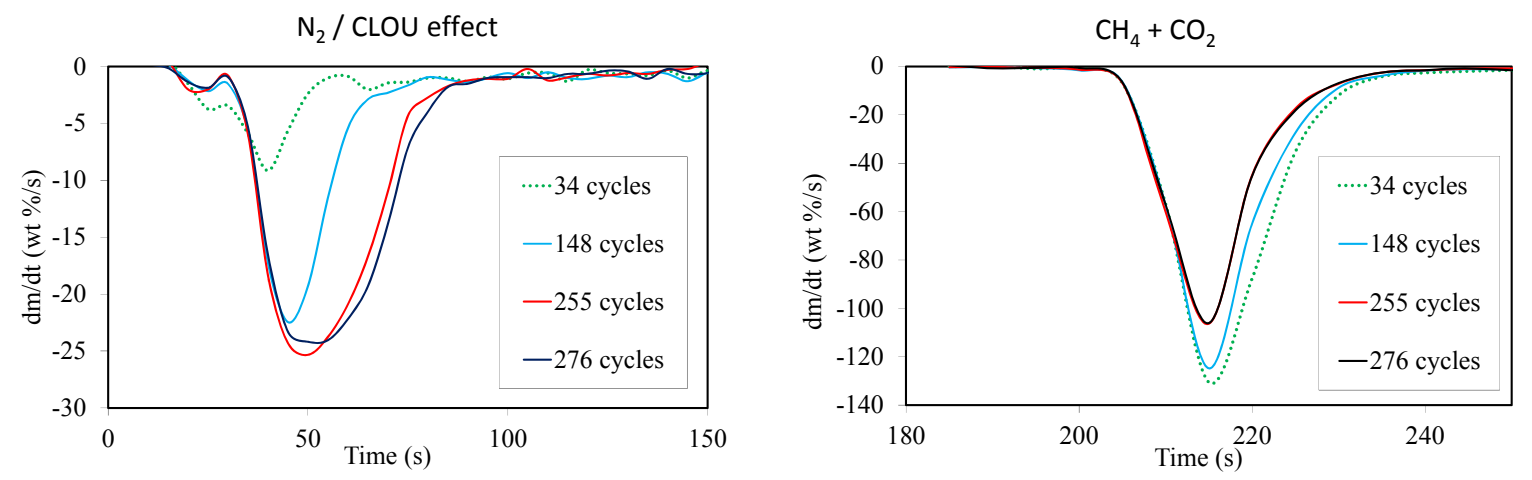

Figure 17: Instantaneous apparent reaction rates measured during the first TGA cycle of the aged samples

\subsubsection{Attrition resistance}

The attrition resistance of the OC was measured before and after the ageing test. No measurement could be performed at intermediate stages due to the large amounts of OC needed to perform the measurements. As can be seen in Figure 18, the TPGI is much larger with aged than with fresh OC, which means that the mechanical resistance of the particles is seriously hampered by the 276 redox cycles. Looking at the particle size distributions of the fresh and aged particles (Figure 19), it actually appears that abrasion is the predominant attrition mechanism in the fresh OC, whereas fragmentation is dominant in the aged sample, creating intermediate size particles. ${ }^{11}$ This is probably due to the extensive cracking of the alumina matrix observed by SEM which weakens the overall mechanical resistance of the particles and triggers their fast breakage, hence the low TPGI difference for these particles after 2 or 3 hours jet cup test duration.

Forero et al. observed that, with lab made $\mathrm{CuO} / \mathrm{Al}_{2} \mathrm{O}_{3}$ particles, the generation of fines was high at the beginning of the different tests they performed, then the attrition lowered down to an acceptable level, but it increased suddenly after a certain time, which depended upon the temperature of the air and fuel reactors. ${ }^{17}$ Cabello et al. reported the same behavior at $900^{\circ} \mathrm{C}$ 
with the same OC as that tested in this study, ${ }^{9}$ and it is highly likely that the morphological evolution of the particles shall reduce the promising lifetime of the particles calculated from the loss of fines (c.f. 3.1).

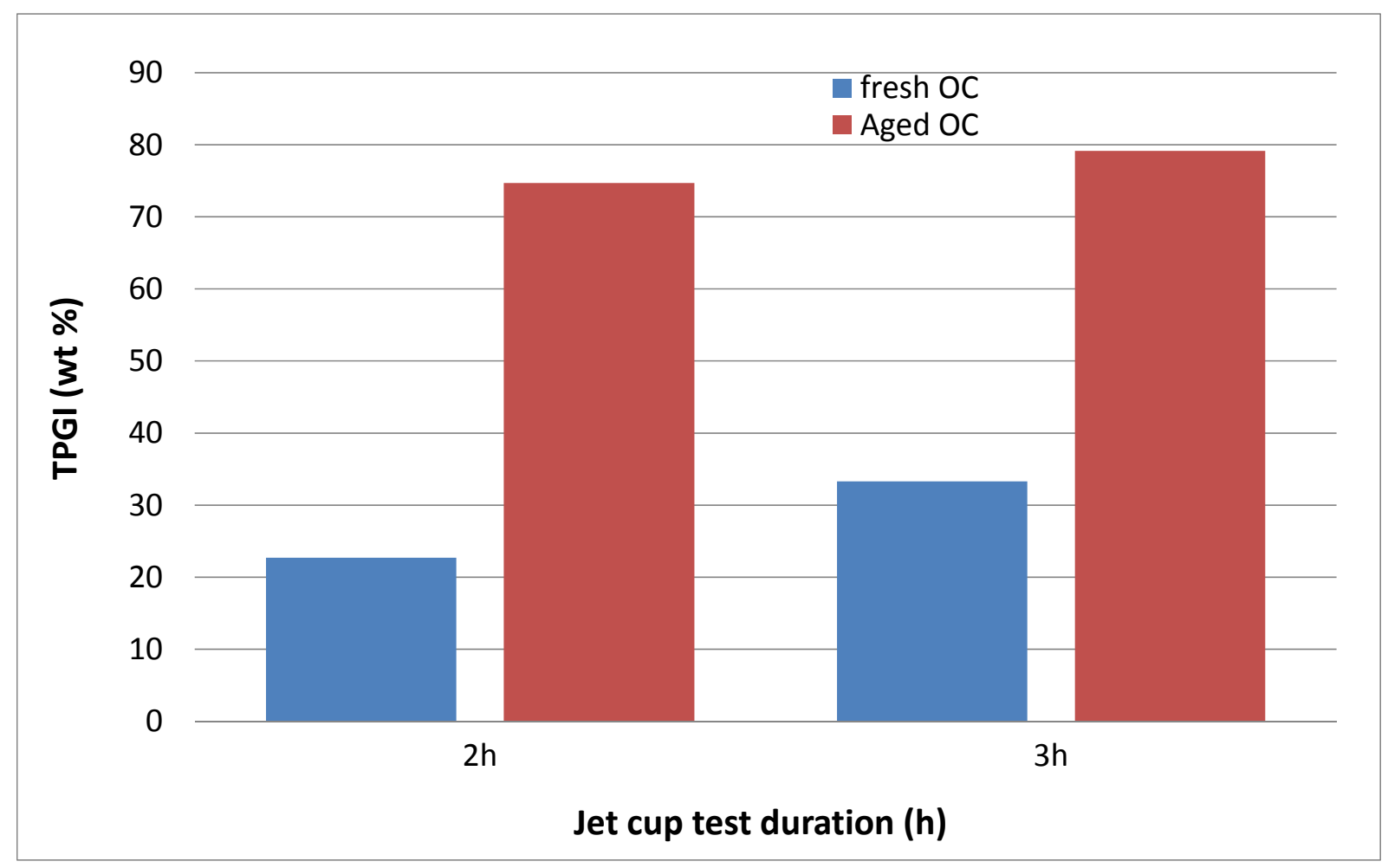

Figure 18: Total Particles Generated Index for fresh and aged OC after 2 and 3 hours jet cup tests
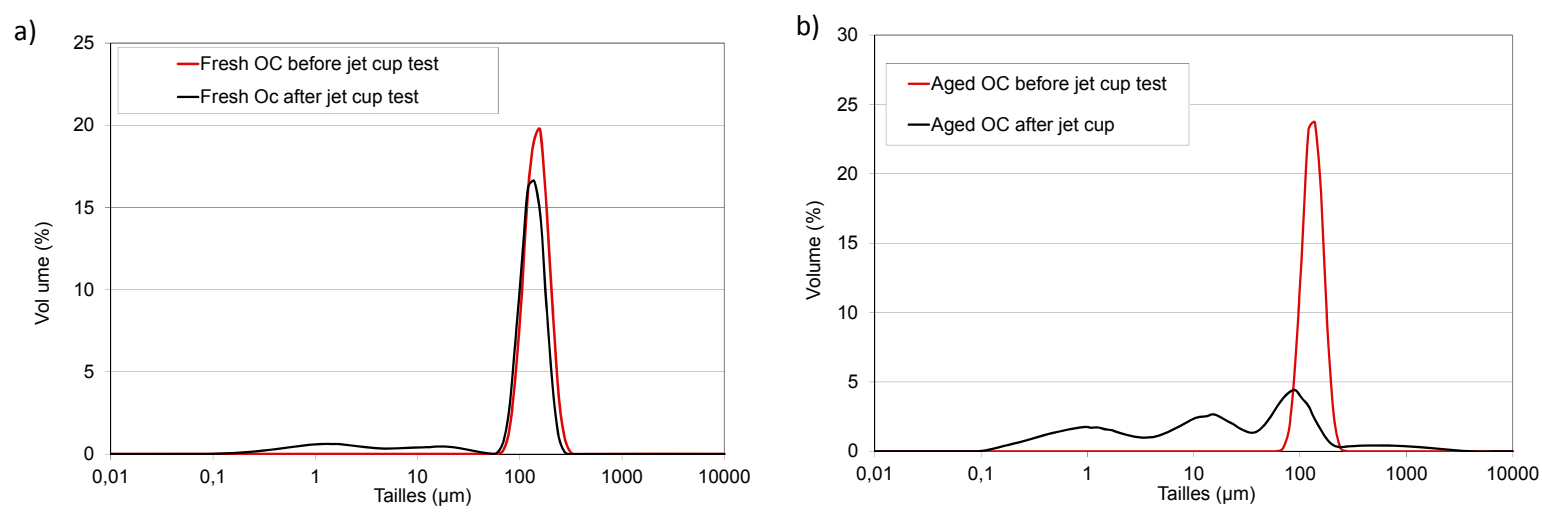

Figure 19: Initial and final particle size distribution for a test with $50 \mathrm{~g}$ of OC during $2 h$; a) fresh OC, b) aged OC 


\subsection{Discussion}

As mentioned earlier, the particles were first circulated with air injection in AR1 and AR2 at $800^{\circ} \mathrm{C}$, and with nitrogen in $\mathrm{FR}$ at $850^{\circ} \mathrm{C}$. Under such conditions, oxygen might be released in the FR, but the gas composition was not monitored, and no sampling of the particles was performed prior to methane injection. In a later test run with the same fresh OC, circulation was performed under the same conditions for $7 \mathrm{~h}$ and the particles from the FR were sampled for analysis prior to combustion: SEM cross-cut section analysis showed no visible morphological evolution, and copper was still well dispersed within the particles, while most of the $\mathrm{CuO}$ crystallites at the surface of the particles were eliminated with the fines. This means that some CLOU occurred to a small extent during preliminary cycling, but it did not modify copper dispersion within the particles. XRD analysis showed that $\mathrm{CuO}$, $\mathrm{CuAl}_{2} \mathrm{O}_{4}, \delta-\mathrm{Al}_{2} \mathrm{O}_{3}$ and $\alpha-\mathrm{Al}_{2} \mathrm{O}_{3}$ were present, but no $\mathrm{CuAlO}$. Interestingly, no more $\gamma-\mathrm{Al}_{2} \mathrm{O}_{3}$ was detected despite the short cycling time at a rather low temperature. Indeed the formation of $\delta-\mathrm{Al}_{2} \mathrm{O}_{3}$ from $\gamma-\mathrm{Al}_{2} \mathrm{O}_{3}$ is reported to occur at $850^{\circ} \mathrm{C}$, and that of $\alpha-\mathrm{Al}_{2} \mathrm{O}_{3}$ from $\delta-\mathrm{Al}_{2} \mathrm{O}_{3}$ at $1150^{\circ} \mathrm{C} .{ }^{18}$ Also, the latter transformation is supposed to occur via formation of $\theta-\mathrm{Al}_{2} \mathrm{O}_{3}$, which was never detected in this study.

In the ageing experiment, it is likely that most of the copper has reacted with the alumina to form the spinel during the two days cycling under air and nitrogen. Both $\gamma-\mathrm{Al}_{2} \mathrm{O}_{3}$ and $\delta-\mathrm{Al}_{2} \mathrm{O}_{3}$ crystallize in a tetragonally distorted spinel lattice with cationic defects, into which cations such as $\mathrm{Cu}^{2+}$ can easily be inserted. ${ }^{18,19}$ Upon heating up to $900^{\circ} \mathrm{C}$ prior to combustion, since copper is initially well dispersed within the porosity of the particles, its insertion into the $\gamma$ - or $\delta-\mathrm{Al}_{2} \mathrm{O}_{3}$ lattice to form $\mathrm{CuAl}_{2} \mathrm{O}_{4}$ should also be facilitated. ${ }^{19}$

XRD analysis of the particles shows a continuous phase evolution during the ageing experiment. After 34 cycles, significant amounts of $\mathrm{CuAl}_{2} \mathrm{O}_{4}$ is detected, as well as $\delta-\mathrm{Al}_{2} \mathrm{O}_{3}$, and low amounts of $\alpha-\mathrm{Al}_{2} \mathrm{O}_{3}$ and free $\mathrm{CuO}$. As the number of cycles increases, the proportions 
of $\mathrm{CuAl}_{2} \mathrm{O}_{4}$ and $\delta-\mathrm{Al}_{2} \mathrm{O}_{3}$ decrease, while those of $\alpha-\mathrm{Al}_{2} \mathrm{O}_{3}$ and $\mathrm{CuO}$ increase. After reduction of $\mathrm{CuAl}_{2} \mathrm{O}_{4}$, some of the metallic copper that is formed can spread at the surface of the pores, considering its low melting temperature. Indeed, the Hüttig and Tammann temperatures, which are used to semi-empirically describe the temperatures at which sintering does occur in supported metal catalysts, ${ }^{20}$ are directly proportional to the melting temperature. When the Hüttig temperature is reached, metal atoms become mobile at the surface of the pores, and above the Tammann temperature, entire crystallites can migrate along said surface. ${ }^{21}$ The ageing test temperature $\left(900^{\circ} \mathrm{C}\right)$ is well above the Hüttig and Tammann temperatures of copper $\left(134^{\circ} \mathrm{C}\right.$ and $405^{\circ} \mathrm{C}$, respectively), and reduced copper atoms or particles shall easily sinter to minimize their surface free energy, gradually forming metallic $\mathrm{Cu}$ nodules inside the OC's porosity. During the subsequent oxidation step, $\mathrm{CuAl}_{2} \mathrm{O}_{4}$ can be formed again, provided enough $\delta-\mathrm{Al}_{2} \mathrm{O}_{3}$ is within reasonable distance of $\mathrm{Cu}$ to react with it. At some stage, solid state diffusion of $\mathrm{Cu}^{2+}$ inside the $\mathrm{CuAl}_{2} \mathrm{O}_{4}$ and/or $\delta-\mathrm{Al}_{2} \mathrm{O}_{3}$ matrix might become rate limiting, since the surface area of the particles decreases drastically with the number of cycles, making it more difficult for mobile species to reach each other. Some of the copper that cannot react with $\delta-\mathrm{Al}_{2} \mathrm{O}_{3}$ is oxidized into $\mathrm{CuO}$, while some $\delta-\mathrm{Al}_{2} \mathrm{O}_{3}$ is converted to $\alpha-\mathrm{Al}_{2} \mathrm{O}_{3}$, which probably does not form the spinel under the CLC conditions, seeing that it accumulates with time. As the number of cycles increases, the size of the copper nodules increases (as observed by SEM analysis) to further minimize their surface free energy and more $\mathrm{CuO}$ is formed. Figure 20 shows a sketch representing the proposed mechanism for the formation of copper nodules on the surface of a primary particle during one redox cycle.
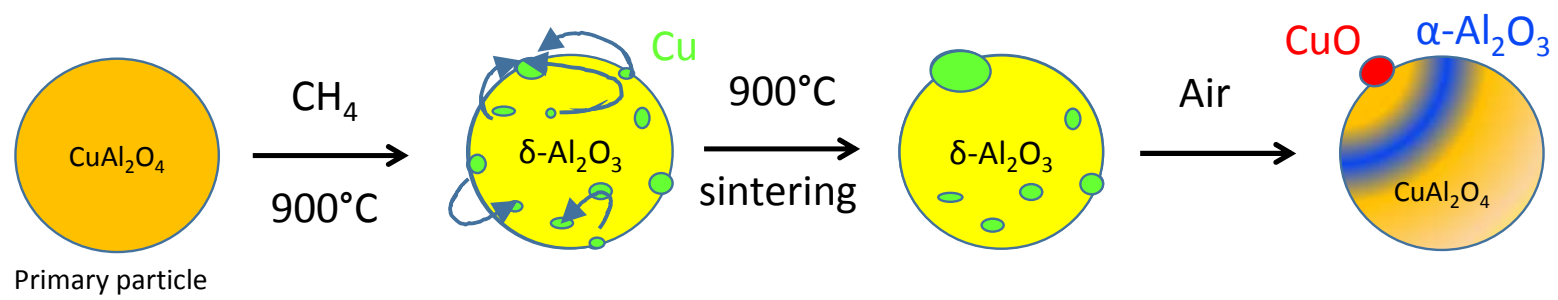

Figure 20: Tentative mechanism for the formation of copper nodules during redox cycles 
At the end of the experiment, no more $\delta-\mathrm{Al}_{2} \mathrm{O}_{3}$ is detected by XRD, but some spinel $\mathrm{CuAl}_{2} \mathrm{O}_{4}$ is still present. Following the proposed transformation route, it is likely that more cycling would have ended up in particles with $\mathrm{CuO}$ and $\alpha-\mathrm{Al}_{2} \mathrm{O}_{3}$ only.

The formation of $\alpha-\mathrm{Al}_{2} \mathrm{O}_{3}$ is reported to occur above $1150^{\circ} \mathrm{C},{ }^{18}$ which is higher than the process temperature. However, both copper oxidation and reduction are exothermic, which might allow the local temperature to increase enough to lead to $\alpha-\mathrm{Al}_{2} \mathrm{O}_{3}$ formation. It is well known that the high temperature sintering of mesoporous transition aluminas results in macroporous $\alpha-\mathrm{Al}_{2} \mathrm{O}_{3}$, which occurred during the ageing test. However, the formation of the macroporous $\alpha-\mathrm{Al}_{2} \mathrm{O}_{3}$ corolla is puzzling : it forms over the first 34 cycles, and copper is excluded from this external layer. One would expect this layer to expand gradually, cycle after cycle, but SEM analysis shows that its thickness is more or less constant for the rest of the test. The size of the macropores in the corolla however does increase with time, due to sintering of alumina. One interesting feature about this corolla is that it seems to prevent the cracks from debouching at the surface of the particles, and in this sense it probably has a stabilizing effect on the particles, avoiding their fragmentation. The attrition resistance however is very much diminished by the presence of cracks inside the particles. The mechanism of cracks formation is probably linked to the phase changes observed during the test, possibly when the cubic close-packed lattice of $\delta-\mathrm{Al}_{2} \mathrm{O}_{3}$ transforms into the hexagonal close-packed lattice of $\alpha-\mathrm{Al}_{2} \mathrm{O}_{3}$.

The first two days of cycling at high temperature with CLOU might explain the corolla formation, but this would have to be further investigated.

Full conversion of methane to $\mathrm{CO}_{2}$ and water was achieved initially with an $\mathrm{OC} /$ fuel ratio of 1.2 at $900^{\circ} \mathrm{C}$, but methane conversion started to decrease after 10 hours, to gradually reach $90 \%$ (Figure 2), despite keeping constant gas and solid residence times in the fuel reactor. The 
$\mathrm{CuO}$ loss at the beginning could explain some of the methane conversion decrease, but only at the beginning of the test. As XRF analysis shows, $\mathrm{CuO}$ decreases sharply between fresh $\mathrm{OC}$ and the first sample (at 34 cycles, when $\mathrm{CH}_{4}$ conversion is still at $99.7 \%$ ), but then the $\mathrm{Cu}$ content is more or less stable. After $160 \mathrm{~h}$, methane conversion stabilizes at about $90 \%$ conversion, but large amounts of $\mathrm{H}_{2}$ and $\mathrm{CO}$ are produced, which implies that steam methane reforming (reaction (3)) contributes to methane conversion. Methane decomposition (reaction (4)) could also explain the formation of hydrogen, since (reduced) copper is a known, albeit not most active, catalyst for methane thermal decomposition. ${ }^{22}$ In that case, carbon would deposit on the particles, which would then be oxidized to $\mathrm{CO}$ and/or $\mathrm{CO}_{2}$ in the air reactors. No $\mathrm{CO}$ nor $\mathrm{CO}_{2}$ were detected in AR1 and AR2, which either means that methane decomposition does not occur under the conditions of the test, or that the reverse Boudouard reaction (reaction (5)) consumes all the coke formed. It is also possible that the decrease of the oxygen availability over time favors the catalytic reactions to the detriment of the methane oxidation reactions. The residence time of the gas and the solid phases being kept constant, this reversal of the predominant reactions lead to a progressive increase of the production of hydrogen and carbon monoxide and a decrease of carbon dioxide production.

$$
\begin{array}{lr}
\mathrm{CH}_{4}+\mathrm{H}_{2} \mathrm{O} \rightarrow \mathrm{CO}+3 \mathrm{H}_{2} & \text { reaction (3) } \\
\mathrm{CH}_{4} \rightarrow \mathrm{C}+2 \mathrm{H}_{2} & \text { reaction (4) } \\
\mathrm{C}+\mathrm{CO}_{2} \rightarrow 2 \mathrm{CO} & \text { reaction (5) }
\end{array}
$$

Besides reactions (3) to (5), methane, carbon monoxide and hydrogen can react with the OC hrough reactions (6) to (11).

$$
\begin{array}{lr}
\mathrm{CH}_{4}+4 \mathrm{CuO} \rightarrow \mathrm{CO}_{2}+2 \mathrm{H}_{2} \mathrm{O}+4 \mathrm{Cu} & \text { reaction (6) } \\
\mathrm{CO}+\mathrm{CuO} \rightarrow \mathrm{CO}_{2}+\mathrm{Cu} & \text { reaction (7) } \\
\mathrm{H}_{2}+\mathrm{CuO} \rightarrow \mathrm{H}_{2} \mathrm{O}+\mathrm{Cu} & \text { reaction (8) }
\end{array}
$$




$$
\begin{array}{lc}
\mathrm{CH}_{4}+4 \mathrm{CuAl}_{2} \mathrm{O}_{4} \rightarrow \mathrm{CO}_{2}+2 \mathrm{H}_{2} \mathrm{O}+4 \mathrm{Cu}+4 \mathrm{Al}_{2} \mathrm{O}_{3} & \text { reaction (9) } \\
\mathrm{CO}+\mathrm{CuAl}_{2} \mathrm{O}_{4} \rightarrow \mathrm{CO}_{2}+\mathrm{Cu}+\mathrm{Al}_{2} \mathrm{O}_{3} & \text { reaction (10) } \\
\mathrm{H}_{2}+\mathrm{CuAl}_{2} \mathrm{O}_{4} \rightarrow \mathrm{H}_{2} \mathrm{O}+\mathrm{Cu}+\mathrm{Al}_{2} \mathrm{O}_{3} & \text { reaction (11) }
\end{array}
$$

As already discussed, the decrease of reactivity of the OC cannot be explained solely by the loss of surface area over time. Deactivation of the OC with time could be due to slowing down redox kinetics, lowering oxygen transfer capacity, or both. Indeed, the quantity of oxygen released by the OC decreases strongly over time, from $2.26 \mathrm{wt} \%$ down to $1.35 \mathrm{wt} \%$, which might be due to lower oxygen transfer capacity. However, TGA measurements show that the oxygen transfer capacity of the OC corresponds roughly to the maximum amount of oxygen that can be delivered by the copper present in the particles (as measured by XRF), and that the instantaneous apparent reduction rate decreases with the number of cycles. When the apparent reduction rate stabilizes (at 255 and 276 cycles), so does the conversion of methane, and the BET surface area does not evolve significantly any more. The observed deactivation must hence be due to modified solid/gas reaction rate which is probably controlled by diffusion limitation caused by sintering of copper-containing crystallographic phases inside the particles.

Considering the spinel phase as the major initial active component of the OC, its reduction by methane must be fast, since full combustion is achieved in the beginning, when the particles are mainly mesoporous. After 34 cycles, a little $\mathrm{CuO}$ has formed, and the size of the copper containing nodules is relatively small: no $\mathrm{CO}$ nor $\mathrm{H}_{2}$ are observed. After 148 cycles, more $\mathrm{CuO}$ has formed and the size of the copper containing nodules has increased: some $\mathrm{CO}$ and $\mathrm{H}_{2}$ are formed. Between these two sampling points, the BET surface area has not changed much, yet methane conversion decreased sharply. A major difference between both samples is their pore size distribution (Figure 12, Figure 13). After 34 cycles, the particles are still predominantly mesoporous, ensuring good gas distribution to the active oxides, whereas after 
148 cycles, the porosity is mainly made up of large macropores, lowering gas accessibility to the active oxides.

At 255 and 276 cycles, the particles are only macroporous, the surface area is very low, more $\mathrm{CuO}$ has formed and the size of the copper containing nodules has increased even more, leading to the formation of large amounts of $\mathrm{CO}$ and $\mathrm{H}_{2}$. As larger $\mathrm{CuO}$ and $\mathrm{CuAl}_{2} \mathrm{O}_{4}$ nodules with hardly any porosity are formed inside the particles, their reduction by methane becomes more difficult. Upon reduction of the external surface of the nodules, metallic $\mathrm{Cu}$ forms, which can catalyze reaction (3), explaining the increase in $\mathrm{CO}$ and $\mathrm{H}_{2}$ formation and the fact that methane conversion does not decrease any more.

\section{Conclusions}

A copper based oxygen carrier prepared by impregnation of commercially available alumina particles using industrially-relevant manufacturing equipment has been aged in IFPEN's $10 \mathrm{~kW}_{\text {th }}$ CLC pilot unit. Methane combustion was performed at $900^{\circ} \mathrm{C}$ for $160 \mathrm{~h}$ with an $\mathrm{OC} /$ fuel ratio of 1.2 , until loss of solids made it impossible to run the test.

Full methane conversion to $\mathrm{CO}_{2}$ and water was achieved in the early stage of the experiment, but the combustion efficiency started to decrease after about $10 \mathrm{~h}$ run. The methane conversion dropped down to $90 \%$ at the end of the ageing test, at which point lots of $\mathrm{CO}$ and $\mathrm{H}_{2}$ were also obtained due to steam methane reforming.

The particles were thoroughly characterized at various stages of the ageing experiment, giving rise to a proposed pathway explaining the observed deactivation of the particles:

Initially, the particles are made of $\mathrm{CuO}$ and $\gamma-\mathrm{Al}_{2} \mathrm{O}_{3}$. The $\gamma-\mathrm{Al}_{2} \mathrm{O}_{3}$ is quickly transformed into $\delta-\mathrm{Al}_{2} \mathrm{O}_{3}$ and/or $\mathrm{CuAl}_{2} \mathrm{O}_{4}$ upon fluidized cycling in air at $800^{\circ} \mathrm{C}$ and nitrogen at $850^{\circ} \mathrm{C}$. Heating up the reactors to $900^{\circ} \mathrm{C}$ and starting combustion of methane, the oxidized form of the particles consists mainly of copper aluminate $\left(\mathrm{CuAl}_{2} \mathrm{O}_{4}\right)$ and delta-alumina. Metallic 
copper forms upon reduction, at which point sintering is most likely to occur. Upon oxidation, a small amount of the copper metal sintered during the previous reduction step cannot diffuse fast enough through the oxides or on the surface of the pores to form the spinel back and is oxidized to $\mathrm{CuO}$. Hereafter, cycle after cycle, the amount of free $\mathrm{CuO}$ builds up, while that of $\mathrm{CuAl}_{2} \mathrm{O}_{4}$ shrinks. Therefore, copper rich nodules build up in size, leading to the observed deactivation of the particles. At the same time, the $\delta-\mathrm{Al}_{2} \mathrm{O}_{3}$ is gradually transformed into $\alpha-\mathrm{Al}_{2} \mathrm{O}_{3}$ due to the exothermicity of both reduction and oxidation of copper oxides, first forming a macroporous layer of $\alpha-\mathrm{Al}_{2} \mathrm{O}_{3}$, the origin of which is still uncertain. $\alpha-\mathrm{Al}_{2} \mathrm{O}_{3}$ formation then continues inside the particles, until no more $\delta-\mathrm{Al}_{2} \mathrm{O}_{3}$ is present. This transformation of alumina is accompanied with the appearance of cracks inside the particles, and the evolution of pore sizes from mesoporous $(\sim 12 \mathrm{~nm})$ to purely macroporous $(\sim 330 \mathrm{~nm})$. This phenomenon together with copper sintering, contributes to the decrease in reaction rates.

The expected lifetime at $900^{\circ} \mathrm{C}$ calculated from the loss of fines measured at the end of the experiment is $7200 \mathrm{~h}$, but the extent of cracking and the low attrition resistance of the aged particles measured with IFPEN's jet cup test challenge this promising figure. The structural and textural evolution of the manufactured $\mathrm{CuO} / \mathrm{Al}_{2} \mathrm{O}_{3}$ oxygen carrier may well limit their effective utilization at $900^{\circ} \mathrm{C}$, unlike at $800^{\circ} \mathrm{C}$, where a promising performance and lifetime has been reported with no cracking of the alumina matrix.

\section{Acknowledgements}

This work was supported by the European Commission Seventh Framework Program under the grant agreement $\mathrm{n}^{\circ} 608571$ (Project acronym SUCCESS).

The Johnson Matthey Company is gratefully acknowledged for supplying the oxygen carrier within the SUCCESS project. 


\section{References}

1 Intergovernmental Panel of Climate Change, Mitigation of Climate Change. Contribution of Working Group III to the Fourth Assessment Report of the Intergovernmental Panel on Climate Change, available at: http://www.ipcc.ch.

2 J. Adanez, A. Abad, F. Garcia-Labiano, P. Gayan and L. F. de Diego, Progress in Energy and Combustion Science, 2012, 38, 215-282.

3 A. Shulman, C. Linderholm, T. Mattisson and A. Lyngfelt, IND ENG CHEM RES, 2009, 48, 7400-7405.

4 P. Knutsson and C. Linderholm, Applied Energy, 2015, 157, 368-373.

5 L. S. Fan, L. Zeng and S. W. Luo, AIChE J., 2015, 61, $2-22$.

6 J. Adanez, P. Gayan, J. Celaya, L. F. de Diego, F. Garcia-Labiano and A. Abad, IND ENG CHEM RES, 2006, 45, 6075-6080.

7 L. F. de Diego, F. Garcia-Labiano, P. Gayan, J. Celaya, J. M. Palacios and J. Adanez, Fuel, 2007, 86, 1036-1045.

8 S. Penthor, F. Zerobin, K. Mayer, T. Proell and H. Hotbauer, Applied Energy, 2015, 145, 52-59.

9 A. Cabello, P. Gayán, A. Abad, L. F. de Diego, F. García-Labiano, M. T. Izquierdo, A. Scullard, G. Williams and J. Adánez, International Journal of Greenhouse Gas Control, 2016, 52, 120-129.

10 S. Rifflart, A. Hoteit, M. M. Yazdanpanah, W. Pelletant and K. Surla, 7Th Trondheim Conference on Co2 Capture, Transport and Storage (2013), 2011, 4, 333-340.

11 B. Amblard, S. Bertholin, C. Bobin and T. Gauthier, Powder Technol., 2015, 274, 455465.

12 B. M. Corbella, L. de Diego, F. Garcia-Labiano, J. Adanez and J. M. Palacios, Energy Fuels, 2006, 20, 148-154.

13 T. Mattisson, H. Leion and A. Lyngfelt, Fuel, 2009, 88, 683-690. 
14 Q. Imtiaz, M. Broda and C. R. Muller, Applied Energy, 2014, 119, 557-565.

15 D. F. Mei, A. Abad, H. B. Zhao and J. Adanez, Fuel Processing Technology, 2015, 133, $210-219$.

16 A. Lambert, P. Briault and E. Comte, in 10TH INTERNATIONAL CONFERENCE ON GREENHOUSE GAS CONTROL TECHNOLOGIES, ed. J. Gale, C. Hendriks and W. Turkenberg, 2011, vol. 4, pp. 318-323.

17 C. Forero, P. Gayan, F. Garcia-Labiano, L. de Diego, A. Abad and J. Adanez, International Journal of Greenhouse Gas Control, 2011, 5, 659-667.

18 Emmanuel Damigos, Ph.D Thesis, Ecole des Mines de Saint Etienne, 1987.

19 Bolt Ph, Harbraken F and Geus J, J.Solid State Chem., 1998, 135, 59-69.

20 A. Cao, R. Lu and G. Veser, PHYSICAL CHEMISTRY CHEMICAL PHYSICS, 2010, 12, $13499-13510$.

21 Ingvild Lovik, NUST, 2001.

22 Hazzim F. Abbas and W.M.A. Wan Daud, Int.J.Hydrogen Energy, 2010, 35, 1160-1190, http://www.sciencedirect.com/science/article/pii/S0360319909018059. 